\title{
Growth and mortality of red sea urchins Strongylocentrotus franciscanus across a latitudinal gradient*
}

\author{
Thomas A. Ebert ${ }^{1, * *}$, John D. Dixon ${ }^{1}$, Stephen C. Schroeter ${ }^{1}$, Peter E. Kalvass ${ }^{2}$, \\ Neil T. Richmond ${ }^{3, \pm}$, W. Alex Bradbury ${ }^{4}$, Douglas A. Woodby ${ }^{5}$ \\ 'Department of Biology, San Diego State University, San Diego, California 92182-4614, USA \\ ${ }^{2}$ California Department of Fish and Game, 19160 S. Harbor Dr., Fort Bragg, California 95437, USA \\ ${ }^{3}$ Oregon Department of Fisheries and Wildlife, PO Box 5430, Charleston, Oregon 97420, USA \\ ${ }^{4}$ Washington Department of Fish and Wildlife, 1000 Point Whitney Rd., Brinnon, Washington 98320, USA \\ ${ }^{5}$ Alaska Department of Fish and Game, PO Box 240020, Douglas, Arkansas 99824-0020, USA
}

\begin{abstract}
Growth and survival of the red sea urchin Strongylocentrotus franciscanus were studied at 18 sites from southern California to Alaska, USA. Growth was determined using tetracycline tagging and was modeled using the Tanaka growth equation. Survival rates were estimated using size-frequency distributions and growth parameters. Using log-linear analysis, it was determined that growth transitions differed among sites $(p \ll 0.001)$ but there was no north-south difference $(p>0.80)$. Para meters for the Tanaka growth function were estimated for all data combined $(N=2714)$. Residuals for sites showed no latitudinal trend and so results were consistent with the log-linear analysis. Relative jaw (demi-pyramid) size, measured as the allometric exponent $\beta$ in jaw length as a function of test diameter, has been shown to be responsive to available food. For red sea urchins, $\beta$ was negatively correlated with growth but there was no correlation of relative jaw size with latitude, which suggests that latitudinal differences in food availability do not exist. In contrast with annual growth rates, annual survival rates were correlated with latitude and were higher in the north. Mean annual survival probability was $0.93 \mathrm{yr}^{-1}$ from northern California to Alaska and $0.77 \mathrm{yr}^{-1}$ in southern California. Likely causes for changes in survival rate with latitude are disease and temperature-related stress. This paper provides the basis for development of hypotheses for size and survival differences between northern and southern populations of red sea urchins and, potentially, for other marine species with planktonic larvae
\end{abstract}

KEY WORDS: Latitudinal cline - Tanaka growth model - Log-linear model - Survival - Sea urchin Strongylocentrotus franciscanus . Tetracycline

\section{INTRODUCTION}

Latitudinal patterns of growth and survival have long been a source of fascination for students of both theoretical and applied ecology. Trends of growth and longevity have been reported for a wide range of spe-

\footnotetext{
- This paper is dedicated to the memory of Neil Richmond, who died while conducting an underwater sea urchin survey on the Oregon coast

-E-mail: tebert@sunstroke.sdsu.edu

tDeceased
}

cies and the conventional presentation has been that both growth and mortality increase with decreasing latitude (Bullock 1955). Temperature is considered to be the driving force for latitudinal changes (Bullock 1955, Frank 1975, Lonsdale \& Levinton 1985, Harrington 1987), and a negative relationship between survival and temperature has interested biologists for decades. In an early review of work with Drosophila, Pearl (1928) discussed the relationship between temperature and survival and, more recently, Pauly (1980) has shown a correlation between temperature and mortality in fish. Survival, growth, and temperature 
relations for a variety of invertebrates have been reviewed by Kinne (1970), and the pattern is a positive relationship between growth and mortality and temperature.

Although latitudinal relationships have been discussed for at least 6 decades, major patterns remain unclear. Patterns of life-history traits associated with latitude can be seen only through studies that span substantial portions of the distribution of species and lack of such studies has hindered our understanding of the evolution of growth and survival plasticity.

The purpose of the work we report here is to explore the spatial pattern of growth and survival of an abundant marine species, the red sea urchin Strongylocentrotus franciscanus. We studied populations from Ketchikan, Alaska, to southern California, USA, which represents a substantial portion of the geographic range of this species. Durham et al. (1980) give the geographic distribution as northern Japan to Isla Cedros, Baja California, Mexico. The Japan record, however, is based on Mortensen (1943), who used a plate in a publication by Yoshiwara to declare that $S$. franciscanus was present in Hokkaidō. There seem to be no other records of S. franciscanus in Japan. Bazhin (1998) doubts that it is present in the western Pacific because in a study of the genus Strongylocentrotus in Russian and adjacent waters he examined over 29000 specimens and did not find $1 S$. franciscanus. Accordingly, we will use Kodiak Island, Alaska, USA (57 $\mathrm{N}$, $153^{\circ} \mathrm{W}$ ) as the extreme limit (Mortensen 1943). One of us ( $S$. C. Schroeter) has observed $S$. franciscanus in Prince William Sound, Alaska, and this would be the northern limit $\left(60.5^{\circ} \mathrm{N}, 147^{\circ} \mathrm{W}\right)$. The southern limit at Isla Cedros off Baja California, Mexico, $\left(28^{\circ} 15^{\prime} \mathrm{N}\right)$ is not correct because $S$. franciscanus has been observed south of Isla Cedros at Punta Rompiente (27 $\left.43^{\prime} \mathrm{N}\right)$ and at Isla Asuncion $\left(27^{\circ} 7^{\prime} \mathrm{N}\right.$ ) (R. McPeak pers. comm.). The total range is about $7000 \mathrm{~km}$ and our study covers about $4700 \mathrm{~km}$ so we include approximately $70 \%$ of the range, which is sufficient for exploring latitudinal trends. In particular, we wish to test the hypothesis that a latitudinal pattern exists for this species with slow growth and long life in the north and fast growth and short life in the south. Our study is not intended to determine the physiological or genetic basis for patterns; these are left for future investigation.

\section{Previous research on Strongylocentrotus franciscanus}

Growth of Strongylocentrotus franciscanus has been studied using a number of techniques. Leighton (1967) and Botsford et al. (1993) studied growth in the laboratory. Swan (1961) measured the growth of sea urchins held in cages and Low (1975) and Schroeter (1978) held sea urchins in pens in the field. Baker (1973) and Low (1975) used mark-recapture methods with invasive tags threaded into the test. Ebert (1977), Schroeter (1978), Ebert \& Russell (1992, 1993), Rowley (1990), and Bureau (1996) used mark-recapture with tetracycline and calcein. All of these studies have shortcomings: the number of observations on which growth estimates could be based generally was small and the studies were either conducted under laboratory conditions or at single sites in the field.

Few studies have attempted to estimate mortality rates for Strongylocentrotus franciscanus. Rowley (1990) estimated survival for newly settled sea urchins by observing changes in density. For post-recruitment sizes, survival has been estimated using size-frequency data and growth parameters (Ebert 1975, Ebert \& Russell 1992, 1993, Botsford et al. 1994). As with the studies of growth, these studies estimated survival at single sites and therefore did not allow latitudinal comparisons.

\section{Field and laboratory methods}

Annual growth and mortality of red sea urchins were estimated at sites from southern California to Alaska (Fig. 1). The study was conducted from 1989 through 1994 with sea urchins at different sites tagged during different years. Only 1 southern California coastal site was used; others were around the Channel Islands. In some of the analyses, Point Conception is used as a separation point. The Southern California Bight, south of Point Conception, is much warmer than sites near Fort Bragg, California, and north (Walker et al. 1995). The mean annual sea surface temperature is $17^{\circ} \mathrm{C}$ at San Diego and $16^{\circ} \mathrm{C}$ at Santa Barbara, just south of Point Conception. Just north of the point at Morro Bay, the mean surface temperature is $13^{\circ} \mathrm{C}$ and drops to $11.5^{\circ} \mathrm{C}$ at Fort Bragg, and $10^{\circ} \mathrm{C}$ on the outer coast of Washington. The $3^{\circ} \mathrm{C}$ change in temperature from just north of Point Conception to Washington is the same as the change from one side of the point to the other. Also, Point Conception is the northern point of the bight that includes a major eddy that holds water near shore (Owen 1980) and is a recognized zoogeographic boundary (Briggs 1974).

Collections at sites were made over variable areas but generally were over a $4 \times 200 \mathrm{~m}$ band that was marked with rebar. Following tagging, sea. urchins were returned to the collection site and the following year an area approximately twice the size of the original was searched and all individuals collected. An effort was made to find all individuals at both times and so rocks and boulders were turnod over and 
searched. The lower size limit for finding red sea urchins in proportion to true abundance is about $1.0 \mathrm{~cm}$. All test measurements were made using knifeedged vernier calipers slipped between spines.

Growth was studied by tagging individuals with tetracycline and measuring incremental growth in Aristotle's lantern demipyramids. Tetracycline tagging has proven to be an effective means of marking a variety of invertebrates (Nakahara 1961, Spangenberg \& Beck 1972, Bavestrello et al. 1993, Bigelow 1993) including sea urchins (Kobayashi \& Taki 1969, Ebert 1977, Schroeter 1978, Russell 1987, Rowley 1990, Gage

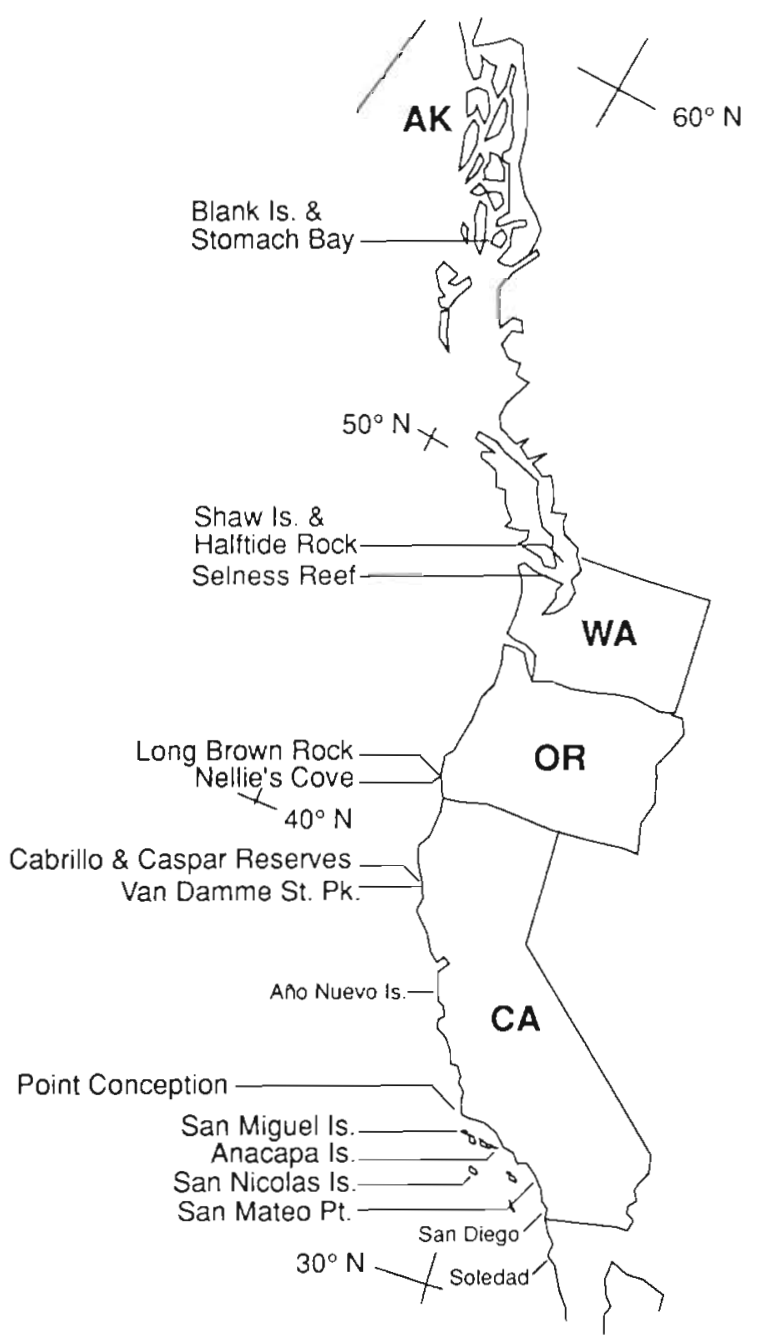

Fig. 1. Locations of study sites for red sea urchins Strongylocentrotus franciscanus; Alaskan sites are near Ketchikan, Washington sites are near Port Angeles (Selness Reef) and Friday Harbor (Halftide Rock and Shaw Island), Oregon sites are near Port Orford, and northern California sites (Pt. Cabrillo, Caspar and Van Damme) are near Fort Bragg; Point Conception is the northern end of the California Bight; Bahia Soledad, San Diego, and Año Nuevo Island are locations where mass mortalities have been observed and are discussed in the text
1992, Kenner 1992, Estes \& Duggins 1995, Bureau 1996). Red sed urchins were measured with vernier calipers and then injected through the peristome using from 0.2 to about $1 \mathrm{ml}$ of a solution of $1 \mathrm{~g}$ of tetracycline in $100 \mathrm{ml}$ of seawater (cf. Ebert 1982). Tetracycline has been shown not to modify growth or survival of Strongylocentrotus franciscanus (Bureau 1996) or of $S$. purpuratus (Ebert 1988). Increased mortality of small S. franciscanus observed by Bureau (1996) was interpreted as due to the tagging procedure itself rather than to tetracycline.

To the extent possible, sea urchins were collected after 1 yr. All calcareous parts were saved from the samples collected at San Nicolas Island, California, (Ebert \& Russell 1992, 1993), but for all other samples, test diameters were measured with vernier calipers and then tests were discarded following the removal of Aristotle's lantern. Calcareous parts were soaked in 5.25 or $10 \%$ sodium hypochlorite bleach to remove soft tissue, soaked in fresh water for 24 h or longer, rinsed and air-dried. Demi-pyramids, referred to as 'jaws', were then examined using ultra-violet illumination to search for the characteristic yellow fluorescence of tetracycline. The end of the jaw closest to the opening of the mouth is called the labial end and the end of the jaw closest to where the esophagus exits Aristotle's lantern is called the esophageal end. The lengths of all jaws were measured and, for tagged jaws, growth increments were measured at both labial and esophageal ends using a calibrated ocular micrometer in a dissecting microscope. The length of the jaw on the day of tagging was estimated as the measured length of the collected jaw minus the growth increments at the labial and esophageal ends. The original jaw length and the jaw length on the day of recapture are the basis for describing growth.

Size-frequency distributions were determined in 2 ways. The first is the obvious method of measuring all individuals that can be found at a site, which was done at the time specimens were tagged. Generally, though not always, all sea urchins that were collected and tagged were also measured. Any small individuals that were collected outside the primary study site were recorded separately so that they would not bias the estimate of the population size-structure on the day of tagging.

When sea urchins were collected after a year in the field, they were measured and Aristotle's lanterns removed for analysis of tetracycline marks. Occasionally, an individual would be crushed during collection and could not be measured, although lanterns could be saved. Also, at some sites not all individuals were measured so some lanterns were saved without the associated diameter measurement. In cases where no test diameter measurement was made, the diameter was 
estimated by using the relationship between diameter and jaw lengths for the rest of the sample and these estimates were added to the size data before plotting the frequency distribution. In general these corrections added only a few individuals.

\section{METHODS OF ANALYSIS}

Two general approaches to growth analysis were used: log-linear analysis and nonlinear regression. Tagged individuals that are recovered after 1 yr can be grouped into size classes based on size at the time of tagging. Individuals in these original states will have different fates during the year including staying in the same size category, growing 1 size class, etc. A table of numbers in original size classes with particular fates after 1 yr is a size transition matrix with sizes classes treated at distinct categories. Study sites and geographic regions are also categories and the question is whether growth during a year is independent of study site and geographic region. The analysis can be thought of as a multi-way contingency table, which is a linear model by log-transforming table values. Application of log-linear models to analysis of transition matrices is presented by Caswell (1989) and is the basis for the calculations we present here using SYSTAT 5.2.1 (1992). The log-linear analysis consisted of an overall analysis followed by comparisons between all possible pairs of sites. Significance levels were adjusted using the Bonferroni method (Milliken \& Johnson 1984) to achieve an experiment error rate of 0.05 .

Previous work on growth of sea urchins has used the Richards function (Ebert 1980a, 1982, Russell 1987, Kenner 1992) or one of the Richards function's more specific models such as the Brody-Bertalanfy (Ebert 1975, Walker 1981, Duineveld \& Jenness 1984, Karlson \& Levitan 1990, Dafni 1992, Botsford et al. 1994, Gage 1995, Gebauer \& Moreno 1995), logistic (Nichols et al. 1985), or Gompertz functions (Gage 1987. Turon et al. 1995) to describe size as a function of age. Inspection of the relationship between original and final jaw lengths in our study suggested that the growth model developed by Tanaka (1982) would be more appropriate than the Richards function (Richards 1959); a similar growth pattern has been observed for Strongylocentrotus polyacanthus (Estes \& Duggins 1995).

Tanaka (1982) states that frequently used growth curves have asymptotes but that growth is often not asymptotic and so he developed his growth model to accommodate continuing growth throughout life. He also wanted to have a growth curve with a general sigmoid shape. The exact reason for selecting the particu- lar function is not clear in his work but probably started with a function expressing growth rate of individuals of size $S$ at time $t$ :

$$
\frac{\mathrm{d} S}{\mathrm{~d} t}=\frac{1}{\sqrt{f(t-C)^{2}+a}}
$$

Eq. (1) reaches a maximum when $c=t$. Growth is slower for both $t<c$ and $t>c$ and is never equal to 0 although it gets closer and closer as $t \rightarrow \infty$. When integrated with respect to $t$, Eq. (1) produces Eq. (2).

$$
S_{t}=\frac{1}{\sqrt{f}} \ln \left(2 f(t-c)+2 \sqrt{f^{2}(t-c)^{2}+f a}\right)+d
$$

Tanaka shows a Walford plot for a bivalve (Theora lubrica) that has the same shape as the data presented in this paper for Strongylocentrotus franciscanus, and a size versus age plot for another mollusc (Laternula anatina) that does not indicate the presence of an asymptote. In a later paper (Tanaka 1988), additional examples are presented for species that show sigmoid growth without an apparent asymptote.

The Tanaka function is complicated but is the only function we have found that adequately describes our data because it can model an early lag and exponential phase followed by a declining growth rate (Ebert \& Russell 1993). Tanaka (1988) provides the biological meanings for the 4 parameters in Eq. (2): $a=$ a parameter related to maximum growth rate, which is approximately $\frac{1}{\sqrt{a}}, c=$ age at which growth rate is maximum, $d=$ a parameter that shifts the body size at which growth is maximum, and $f=$ a measure of the rate of change of the growth rate.

The difference equation for the Tanaka function is

where

$$
S_{t+1}=\frac{1}{\sqrt{f}} \ln \left(2 G+2 \sqrt{G^{2}+f a}\right)+d
$$

and

$$
G=E / 4-f a / E+f
$$

$$
E=\exp \left[\left(f\left(S_{t}-d\right)\right)\right]
$$

Eq. (3) is a bell-shaped curve that is rotated so that it is asymptotic to a $45^{\circ}$ line in a plot of $S_{t+1}$ versus $S_{t}$. How parameters $f, d$ and a influence the growth curve is shown in Fig. 2. Starting values for showing effects of changing parameters were $f=8, d=0$ and $a=8$ and were selected because they are similar to typical values that were estimated for red sea urchins. Each graph in Fig. 2 contains a plot with these starting values together with parameter changes above and below these values. The parameter $f$ was changed in Fig. $2 \mathrm{~A}$ by increasing and decreasing the starting value, 8 , by 6 so one line is for $f=2, d=0$, and $a=8$; another line is drawn using parameter values of $f=14, d=0$, and $a=$ 8. The plots show that increasing $f$ makes plots more leptokurtic, which, in terms of growth, means that 
increasing $f$ prolongs the lag phase of growth as a function of age or the length of time it takes to get to the first inflection point in the Walford plot (Fig. 2). Low values of $f$ would produce a growth curve with a more gentle rise to maximum growth. The size at which growth rate is maximum is also changed and is at a smaller size for large values of $f$.

Changing parameter $d$ (Fig. 2B) shifts the size of maximum growth: negative values show maximum growth at a small size whereas increases in $d$ shift maximum growth rate to ever larger sizes. Changes in parameter a (Fig 2C) show an inverse relationship with maximum growth rate. As parameter a decreases, maximum growth rate increases, but the size at which maximum growth is attained becomes smaller. With the parameters that were used, growth rate was maximum with $a=2$.

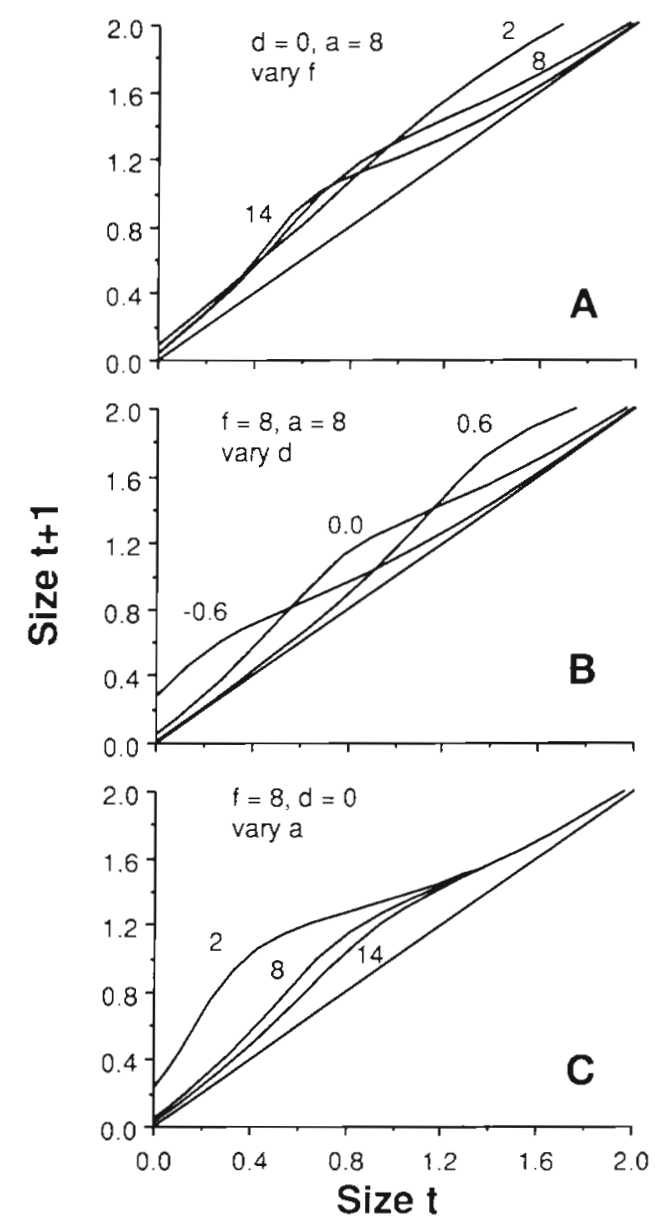

Fig. 2. Simulation of curves for different parameters of the Tanaka function. (A) Parameters $d$ and $a$ held constant at 0 and 8 and $f$ varied $(2,8$, and 14$)$; (B) parameters $f$ and $a$ held constant at 8 and $d$ varied $(-0.6,0$, and +0.6$)$; (C) parameters $f$ and $d$ held constant at 8 and 0 and $a$ varied $(2,8 \text {, and } 14)_{i}$ all 3 graphs have a common curve based on $f=8, d=0$, and $a=8$
Survival of an initial number of individuals, $N_{0}$, was modeled using a simple decaying exponential function:

$$
N_{t}=N_{0} e^{-Z i}
$$

The mortality coefficient, $\mathcal{Z}$ (Eq. 6), was estimated using size-frequency data together with parameters from the Tanaka growth function; annual survival rate, $p_{x}$ is $\mathrm{e}^{-Z}$. Our approach to estimating $Z$, and hence $p_{x}$ makes use of the relationship between mean size, growth and survival in populations with pulsed recruitment (Ebert 1987, 1998, 1999)

$Z$ can be estimated if one knows the mean test diameter, $\overline{D_{T}}$, at some time $T$ following annual recruitment, and size-specific growth rates. The mean size, $D_{T}$, is the sum of the sizes of all individuals of a particular age class $T+t$, multiplied by the number in that age class and divided by the sum of individuals of all ages. It is assumed that sizes at age are normally distributed around a mean size at age, $D_{T+*}$ and so

$$
\overline{D_{T}}=\frac{\sum D_{T+i} N_{t}}{\sum N_{t}}
$$

$T$ is time within a year since annual recruitment; for example, if recruitment was in March and sampling was in July, 4 mo later, $T=4 / 12$ or 0.333 . Note that mean size at age, $D_{T+t}$, can be calculated by using growth parameters estimated from tagged individuals and $\dot{D}_{T}$ is just the mean size of all individuals in the sample; the values of $N_{t}$ are unknown and need to be estimated by assuming a survival model such as Eq. (6).

Time since annual recruitment $(T)$ and size at recruitment $\left(D_{0}\right)$ usually cannot be estimated from existing data or extrapolated with confidence from growth parameters based on tagged juveniles and adults. A solution to this problem is to use the mean of the first mode of a size-frequency distribution as an estimate of $D_{0}$; individuals recruit to the population at size $D_{0}$ on the day of collection which makes the day of collection $T=0$ (Ebert 1987, 1999).

To estimate $Z$ using the Tanaka function, $D_{t}$ is replaced in Eq. (7) by Eq. (2) after converting jaw length to test diameter using the standard allometric equation (Eq. 8). The parameters $\alpha$ and $\beta$ were fitted for each study site using jaw (demi-pyramid) length and test diameter measurements of sea urchins collected at the end of the study period.

$$
Y=\alpha X^{\beta}
$$

With jaw length, $J$ as the independent variable and test diameter, $D$, as the dependent variable, Eq. (8) is:

$$
D=\alpha J^{\beta}
$$

The Tanaka function for diameter, $D_{\tau+l}$, as a function of time since recruitment (Eqs. $2 \& 9$ ) is: 
$D_{\gamma+t}=\alpha\left\{\frac{1}{\sqrt{f}} \ln \left|2 f[(T+t)-c]+2 \sqrt{f^{2}[(T+t)-c]^{2}+f a}\right|+d\right\}^{\beta}$

which provides one of the terms in Eq. (7)

Also in Eq. (7), $N_{1}$ is replaced by Eq. (6), which makes mean size, $\bar{D}_{T}$, a function of diameter growth and survival parameters. One convenient substitution is based on the limit of a sequence of partial sums of $\Sigma \mathrm{N}_{t}$, that is, $\Sigma e^{-Z t}$.

$$
\sum \mathrm{e}^{-z t}=\frac{1}{1-\mathrm{e}^{-z}}
$$

With substitutions for the Tanaka function, Eq. (7) becomes a suitable nonlinear model for estimating $Z$ :

$$
\begin{aligned}
& \overline{D_{\top}}=\left(1-e^{-Z}\right) \sum_{t=0}^{\omega} e^{-Z t} \\
& \alpha\left\{\frac{1}{\sqrt{f}} \ln \left|2 f[(t+T)-c]+2 \sqrt{F^{2}[(t+T)-c]^{2}}+f a\right|+d\right\}^{\beta}
\end{aligned}
$$

$Z$ was estimated for each individual size distribution using the Newton-Raphson algorithm (Ebert \& Russell 1993, Ebert 1998, 1999). The parameter $\omega$ is the final age used in the algorithm and varies with the value of $Z$,

$$
\omega=\frac{-\ln \left(1 \times 10^{-8}\right)}{Z}+0.5
$$

In Eq. (12), growth parameters were determined from tagging and allometry parameters, $\alpha$ and $\beta$, were estimated from measured specimens at each site; the only unknown parameter in Eq. (12) is Z A BASIC computer program to estimate $Z$ from mean size and Tanaka growth parameters, called ZTAN, is given in Ebert (1999) and can be downloaded from http://www.sci.sdsu.edu/Cornered_Rat/.

Relative jaw length has been shown to be indicative of food availability (Ebert 1980b, 1996, Black et al. 1982, 1984, Fansler 1983, Levitan 1989, Bureau 1996). Where food is scarce, jaws tend to be large relative to test diameter. Consequently, the relationship between jaw length and test diameter should reflect food conditions in the field and be correlated with growth rates. The basic allometric equation (Eq. 8) is appropriate for comparing exponents, $\beta$, across samples if adjusted so that all samples have a common value of $\alpha$. We did this by assuming that all sea urchins had similar relative jaw lengths at the time of settlement. Our rationale is that Aristotle's lantern develops within the first week following settlement and urchins cannot begin to feed until the lantern has developed. Test size in $\mathrm{cm}$ can be scaled by dividing all diameter measurements by $0.05 \mathrm{~cm}$, the test diameter at settlement, which was estimated from a sample of 51 settlers $(\bar{X})=0.497 \mathrm{~mm} \pm$ $0.011 \mathrm{SE}$ ) removed from brush collectors deployed at sites in southern California for 1 wk intervals in April
1990 (Ebert et al. 1994). Following a logarithmic transformation, the size at settlement $(0.05 \mathrm{~cm})$ will be equal to 0 [i.e. $\ln (0.05 / 0.05)]$ and jaw size at this point will be the common intercept for sea urchins from all sites. Sea urchins grow in response to local conditions so relative jaw sizes will diverge; that is, slopes for a regression of ln-transformed data will be different.

The estimate of a common initial jaw length $(C)$ was done by nonlinear regression using jaw length $(J)$ as the dependent variable and diameter $(D)$ divided by 0.05 as the independent variable for each sample (Eq. 14).

$$
J=C(D / 0.05)^{\beta}
$$

To stabilize variances, a ln-transformation was first performed:

$$
\ln J=\ln C+\beta \ln D-\beta \ln 0.05
$$

Following analysis of all samples, the mean of $\ln C$ was determined and used as the best estimate of a common value. Nonlinear regression was used with this fixed value for $\ln C$ (Eq. 15) to estimate the value of $\beta$ for each sample. The larger the value of $\beta$, the larger the size of the jaw (demi-pyramid) relative to diameter of the test. Larger $\beta$ s should mean poorer food conditions.

Fishing regulations vary by state and could influence estimates of some growth and survival parameters. During our study, regulations in California and Oregon were based on minimum test diameter: $8.3 \mathrm{~cm}$ south of Point Conception and $8.9 \mathrm{~cm}$ north through Oregon. In Washington, there were rotating closed areas with both minimum and maximum size limits. At Selness Reef, the legal sizes were 8.3 to $11.4 \mathrm{~cm}$ and in the San Juan district, legal sizes were 10.2 to $13.3 \mathrm{~cm}$. During the period of our study there was no fishing at our study sites in Alaska because this was before the development of a fishery. Areas in Washington were closed to fishing and so fishing should not have occurred; no poaching was observed or reported.

\section{RESULTS}

Several approaches were used to analyze growth and compare samples from different sites: (1) log-linear analysis using growth transitions of jaws (demipyramids of Aristotle's lantern); (2) estimation of a single set of Tanaka growth parameters for all data combined, which was followed by analysis of residuals and using the mean residual for each data set as a measure of growth relative to other sites; (3) estimation of growth parameters for each site individually; maximum growth rate, $1 / \sqrt{a}$ ), was used for comparing sites; and (4) correlation of measures of growth $(1$ and 2 above) and relative jaw size, $\beta$ from Eqs. (14) \& (15), with latitude. 
Table 1. Summary of log-linear analysis for growth transitions: differences that are significant at $\leq 0.001$ are shown in boldface; significance criterion based on the Bonferroni method, which insures the maximum experimentwise error rate is $\leq 0.05 ;$ northern sites start on the left of the table

\begin{tabular}{|c|c|c|c|c|c|c|c|c|c|}
\hline & Washington & Oregon & Cabrillo & Caspar & San Miguel & $\begin{array}{c}\text { Anacapa } \\
1992-1993\end{array}$ & $\begin{array}{c}\text { Anacapa } \\
1993-1994\end{array}$ & San Nicolas & San Mateo \\
\hline Alaska & $>0.25$ & $<0.05$ & $>0.05$ & $>0.10$ & $<0.025$ & $>0.10$ & $<0.005$ & $>0.50$ & $>0.05$ \\
\hline Washington & - & $>0.05$ & $<0.001$ & $>0.25$ & $<0.001$ & $>0.05$ & $<0.001$ & $>0.05$ & $<0.001$ \\
\hline Oregon & & - & $<0.001$ & $>0.99$ & $<0.025$ & $<0.025$ & $<0.001$ & $<0.005$ & $<0.001$ \\
\hline Cabrillo & & & - & $<0.025$ & $<0.01$ & $<0.05$ & $>0.10$ & $>0.05$ & $>0.99$ \\
\hline Caspar & & & & - & $>0.10$ & $>0.50$ & $>0.10$ & $>0.25$ & $>0.90$ \\
\hline San Miguel & & & & & - & $<0.001$ & $<0.001$ & $<0.01$ & $<0.001$ \\
\hline Anacapa 199 & -1993 & & & & & - & $<0.05$ & $<0.025$ & $>0.10$ \\
\hline Anacapa 199 & -1994 & & & & & & - & $<0.001$ & $>0.10$ \\
\hline San Nicolas & & & & & & & & - & $<0.001$ \\
\hline
\end{tabular}

\section{Log-linear analysis}

Growth comparisons using log-linear analysis were based on grouping original jaw sizes into $0.2 \mathrm{~cm}$ categories and scoring the fates of these individuals after 1 yr. In addition to size, sea urchins were classified by study site and geographic location (north or south) so there were 4 ways of classifying individuals: original size, site, location, and fate. The south versus north division into geographic locations separated sites south of Point Conception, California, from sites from northern California to Alaska. The question of interest is whether the fate of individuals in a particular initial size category is independent of the site or location of the collection. An initial analysis was conducted to test for local differences. Washington sites could be combined as could sites in Oregon and in Alaska. California sites could not be combined nor was there a north versus south difference in California so sites were kept separate.

The comparisons between Alaska, Washington, Oregon, and California sites were done using 3 possible transitions: staying in the original size class (Fate 1), growing to the next size class (Fate 2) or growing enough to skip a size class (Fate 3 ). Comparisons of all sites started with a size class of $\leq 0.60 \mathrm{~cm}$ and ended with a class $>2.00 \mathrm{~cm}$ for a total of 9 size classes.

The log-linear analysis showed large differences in growth transitions between sites $\left(G^{2}=122.6\right.$, df $=18$, $\mathrm{p} \ll 0.001$ ). Detailed pairwise comparisons (Table 1) showed no latitudinal pattern to the differences and this is borne out by an analysis including north and south locations $\left(G^{2}, \mathrm{df}=2, \mathrm{p}>0.80\right)$. Growth transitions of sea urchins from Alaska were similar to the transitions in both northern and southern California and samples that were close together, such as those gathered at 2 areas at Anacapa Island in southern California, were as different as samples gathered 1000 s of kilometers apart. All analyses were done with transi- tion tables that had many counts less than 5, which means that it is necessary to be cautious in interpreting results; the fact, however, that we pick up highly significant differences argues that we have sufficient power to detect a latitudinal pattern if one existed.

A potential weakness of the log-linear analysis is that size classes are not natural categories like sex or age and so internal structure of size classes may increase variability in transitions and hence lead to concluding incorrectly that differences do not exist when, in fact, they do. A different approach is to use a growth model although, as will be shown, nonlinear growth models have other problems with respect to comparing samples and so conclusions are best based on use of both analyses.

\section{Overall analysis of growth with common Tanaka parameters}

A total of 2714 tagged red sea urchins was recovered from all sites combined and these individuals were used to estimate the parameters $f, d$, and a of the Tanaka function (Table 2). The overall fit is good with

Table 2. Analysis of tagged red sea urchins from all sites combined; $N=2714_{i}$ the Tanaka growth model is: $J_{t+1}=$ $J_{t+1}=\frac{1}{\sqrt{ } f} \ln \left(2 G+2 \sqrt{G^{2}+f a}\right)+d_{1}$ where $G=E / 4-f a / E+f$ and $\left.E=\exp [\sqrt{f})\left(J_{1}-d\right)\right]_{i}$ parameters $f_{1} d_{1}$ and $a$ were estimated by nonlinear regression (SAS 1988, procedure PROC NLIN); starting values were $f=5, d=-0.1$ and $a=0.4$; tolerance $=$ $10^{-7} ; R^{2}=0.986$

\begin{tabular}{|lrrrr|}
\hline \multirow{2}{*}{ Parameter Estimate } & Asymptotic & \multicolumn{2}{c|}{ Asymptotic 95\% CI } \\
& & SE & Lower & Upper \\
\hline$f$ & 8.23329 & 0.09548 & 8.04607 & 8.42051 \\
$d$ & -0.22187 & 0.00346 & -0.22865 & -0.21508 \\
$a$ & 7.77160 & 0.18689 & 7.40513 & 8.13807 \\
\hline
\end{tabular}




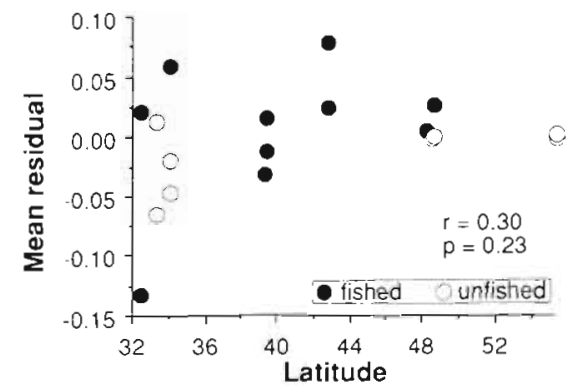

Fig. 3. Mean residual for each site based on the overall Tanaka growth parameters vs latitude mum growth rate; the parameter a is negative (Table 3). We interpret this as a problem in sampling. Had samples included small individuals, we are confident that a maximum would have been observed and the parameter a would have been positive.

Individual Tanaka parameters, $f, d$, and $a$, were plotted versus latitude for individual analyses (Fig. 5). The parameters $f$ and $d$ both are correlated with latitude $(p=0.02)$ but the parameter $a$ is not $(p=0.49)$. As was the case for the mean residuals, there are no differences between samples from fished and unfished areas. Since maximum growth rate is $1 / \sqrt{a}$ (Table 3 ), a lack of correlation between latitude and the parameter a means that maximum growth rates are not correlated

$\mathrm{R}^{2}=0.986$. Values of $f=8.233 \pm 0.095$, $d=-0.222 \pm 0.003$ and $a=7.772 \pm 0.187$ are similar to the values used in the simulations presented in Fig. 2 and indicate the general shape of the growth function; namely, a lag and exponential phase, a period of rapid growth, and a long period of very low and nearly constant growth.

Based on overall parameter estimates of the Tanaka function for all tagged sea urchins, residuals were calculated for each sample. The distribution of mean residuals versus latitude (Fig. 3) shows no correlation with latitude and no separation of fished versus unfished areas. These results support the log-linear analysis that growth is independent of latitude.

In addition to an analysis of residuals, estimates of Tanaka parameters were made for each sample in order to estimate maximum growth rate for purposes of comparing samples. Final versus original jaw lengths were plotted (Fig. 4) together with fitted curves using parameters shown in Table 3. Fitted lines show differences in maximum growth, the sizes of maximum growth, and the flatness or peakedness of the curves. For example, the tagged sea urchins from Anacapa Island, California (Fig. 4), show a very flat curve whereas the curve for red sea urchins at Halftide Rock, Washington, is much more peaked or leptokurtic. Samples from the intertidal zone of San Nicolas Island, California, and the main kelp bed at San Mateo Point, California do not show a peak in the scatter of points in Fig. 4, which means that there is no estimated maxi-

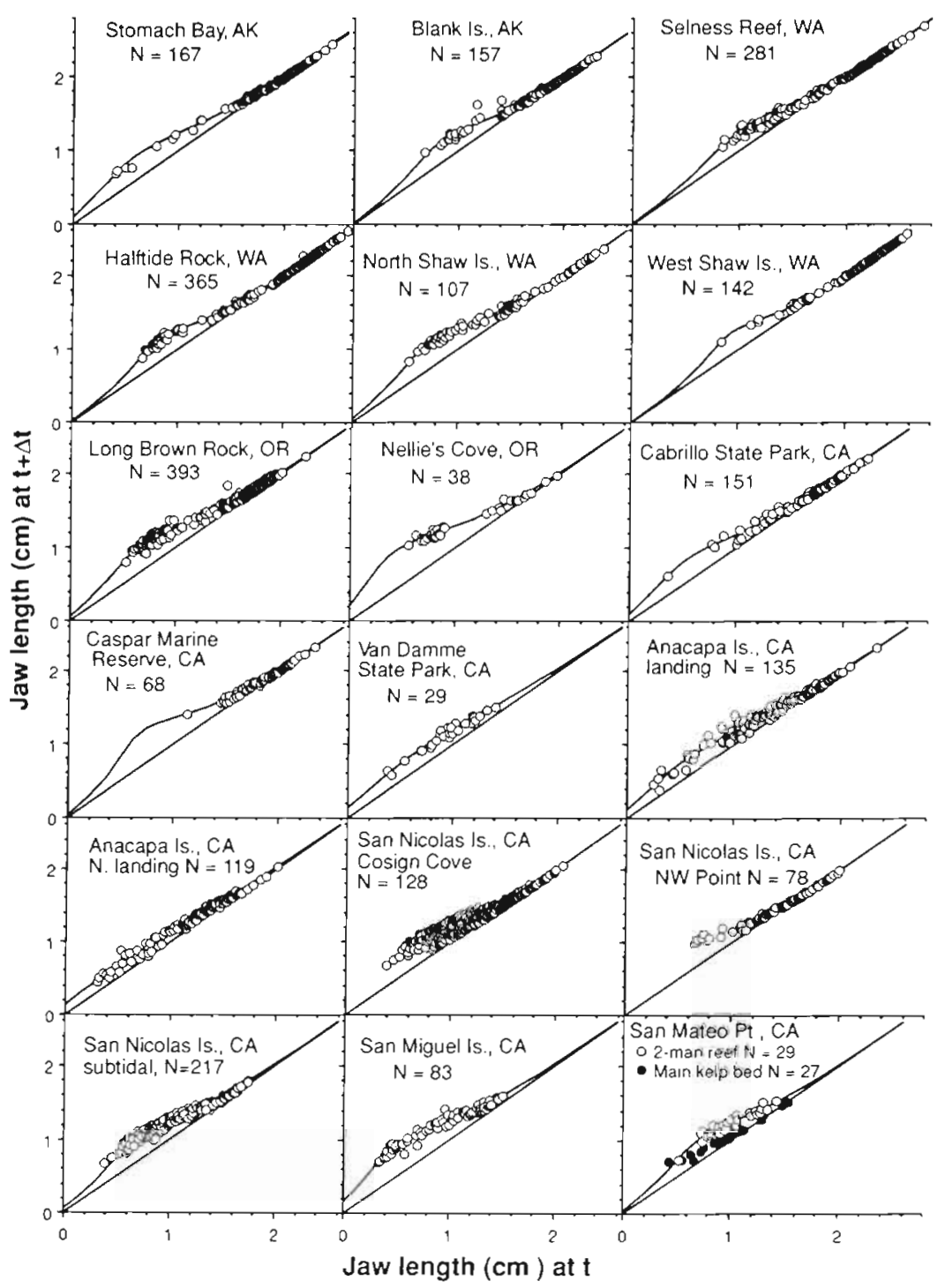

Fig. 4. Strongylocentrotus intermedius. Jaw length at time of collection $(t+\Delta t)$ vs length at tagging $(t)$ for red sea urchins from Alaska to southern California; fitted lines are for the Tanaka function (Tanaka 1982, 1988); parameter values given in Table 3 
Table 3. Tanaka function parameters for Strongylocentrotus franciscanus jaw growth estimated for each site by nonlinear regression (NONLIN, SYSTAT 1992); maximum. growth rate of the jaw, $1 / \sqrt{a}(a)$ is in $\mathrm{cm}$ and converted to growth rate yr ${ }^{-1}$ by multiplying by $365 / \Delta t$

\begin{tabular}{|c|c|c|c|c|c|c|c|}
\hline Site & $N$ & $\Delta t$ & $f \pm \mathrm{SE}$ & $d \pm \mathrm{SE}$ & $a \pm S E$ & $1 / \sqrt{a}$ & $1 / \sqrt{a} \mathrm{yr}^{-1}$ \\
\hline Stomach Bay & 167 & 365 & $7.577 \pm 0.465$ & $-0.252 \pm 0.044$ & $9.320 \pm 0.574$ & 0.3276 & 0.3276 \\
\hline Blank Island & 157 & 365 & $12.302 \pm 1.252$ & $0.091 \pm 0.058$ & $10.580 \pm 0.942$ & 0.3074 & 0.3074 \\
\hline North Shaw Island & 107 & 362 & $9.523 \pm 0.746$ & $-0.009 \pm 0.039$ & $7.056 \pm 0.282$ & 0.3765 & 0.3796 \\
\hline West Shaw Island & 142 & 362 & $15.808 \pm 0.829$ & $0.276 \pm 0.026$ & $9.688 \pm 0.488$ & 0.3213 & 0.3239 \\
\hline Halftide Rock & 365 & 370 & $13.935 \pm 0.553$ & $0.130 \pm 0.018$ & $9.631 \pm 0.200$ & 0.3222 & 0.3179 \\
\hline Selness Reef & 281 & 370 & $11.800 \pm 0.779$ & $0.114 \pm 0.035$ & $14.760 \pm 0.784$ & 0.2603 & 0.2568 \\
\hline Long Brown Rock & 393 & 376 & $8.460 \pm 0.438$ & $-0.069 \pm 0.031$ & $6.971 \pm 0.196$ & 0.3788 & 0.3677 \\
\hline Nellie's Cove & 38 & 380 & $7.590 \pm 1.486$ & $-0.125 \pm 0.102$ & $3.015 \pm 0.784$ & 0.5759 & 0.5532 \\
\hline Van Damme & 29 & 351 & $3.512 \pm 1608$ & $-0.702 \pm 0.289$ & $16.234 \pm 2.196$ & 0.2482 & 0.2581 \\
\hline Cabrillo & 151 & 376 & $8.070 \pm 0.813$ & $-0.318 \pm 0.067$ & $9.665 \pm 1.238$ & 0.3217 & 0.3123 \\
\hline Caspar & 68 & 387 & $12.330 \pm 3054$ & $0.200 \pm 0.155$ & $3.603 \pm 8.599$ & 0.5269 & 0.4969 \\
\hline San Miguel & 83 & 363 & $7.328+1.048$ & $-0.1 .82 \pm 0.069$ & $4.669 \pm 0.301$ & 0.4628 & 0.4653 \\
\hline Anacapa 1992-1993 & 135 & 376 & $5.089 \pm 0.874$ & $-0.586 \pm 0.119$ & $15.391 . \pm 1.856$ & 0.2549 & 0.2474 \\
\hline Anacapa 1993-1994 & 119 & 345 & $2.315+0.722$ & $-1.302 \pm 0.309$ & $32.124 \pm 4.201$ & 0.1764 & 0.1867 \\
\hline San Nicolas, intertidal & 206 & 348 & $8.578 \pm 1.936$ & $-0.577 \pm 0.170$ & $-43.613 \pm 25.501$ & & \\
\hline San Nicolas, subtidal & 217 & 365 & $9.186 \pm 0.725$ & $-0.113 \pm 0.038$ & $7.395 \pm 0.343$ & 0.3677 & 0.3677 \\
\hline San Mateo, 2-man reef & 29 & 391 & $9.791 \pm 2.419$ & $-0.040 \pm 0.108$ & $8.995 \pm 1.018$ & 0.3334 & 0.3112 \\
\hline San Mateo, main kelp bed & 27 & 370 & $4.787 \pm 3.324$ & $-1.151 \pm 0.624$ & $-26.883 \pm 56.167$ & & \\
\hline
\end{tabular}

with latitude. The meaning of the positive correlations for $f$ and $d$ can be understood with reference to Fig. 2 . An increase in parameter $f$ causes a shift of maximum growth rate towards smaller sizes as well as making the curve more peaked. The highest values of $f$ were estimated for Halftide Rock and West Shaw Island (latitude $48^{\circ}$ ) and examination of Fig. 3 shows these to be the most peaked of the fitted lines. Increases in parameter $d$ (Fig. 2) do not change peakedness but shift the size of maximum growth towards larger sizes, the reverse of the action of increasing parameter $f$. Parameters $f$ and $d$ are highly correlated $(\mathrm{r}=0.88, \mathrm{~N}=18$, $\mathrm{p}<0.001$ ) and their antagonistic action in the Tanaka growth function with respect to position of maximum growth rate suggests that some single measure of growth would be better for comparing growth across latitude.

\section{Analysis of relative jaw length}

Nonlinear regression using Eq. (14) was done for each sample to determine $\ln C$, where $C$ is the jaw length at a test diameter of $0.05 \mathrm{~cm}$ (Table 4). The unweighted mean of these estimates was used as the best estimate of a common jaw length for all samples immediately following settlement. The estimate of mean $\ln C$ for all samples is -3.768905 , which is a jaw length of $0.023 \mathrm{~cm}$ for a sea urchin with a test diameter of $0.05 \mathrm{~cm}$.

The value of $\ln C$ was fixed at -3.768905 and regressions redone using $\mathrm{Eq}$. (15) to estimate $\beta$ for each sam- ple (Table 4). The expected relationship between food and $\beta$ is that increases in $\beta$ indicate relatively larger
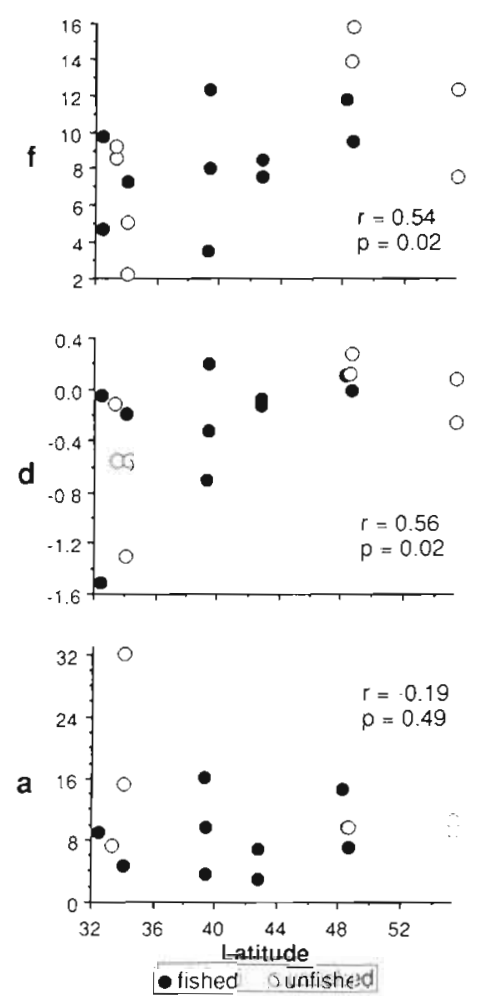

Fig. 5. Relationship between parameters of the Tanaka growth function and latitude $e N=18$ for parameters $f$ and $d$ and $N=16$ for parameter a because samples from San Nicolas Island (intertidal) and San Mateo (main kelp bed) had negative estimates for a 
Table 4. Estimation of jaw length at a test diameter of $0.05 \mathrm{~cm}$, the approximate diameter at settlement; the model used for estimating jaw length is $\ln (j a w)=\ln (C)+\beta \ln (D)-\beta \ln (0.05)$; total $N=6724$; underlined values for $95 \%$ limits for $\ln (C)$ are for samples that lie outside the value of the unweighted mean of $-3.768905 ; \beta$ is the value using the common value for $\ln (C)$

\begin{tabular}{|lccccc|}
\hline Site & $N$ & $\ln (C)$ & $95 \%$ limits & $\beta$ & $95 \%$ limits \\
\hline 1 San Mateo, 2-man reef & 111 & -3.7766 & -3.8449 to -3.7082 & 0.8185 & 0.8170 to 0.8201 \\
2 San Mateo, main kelp bed & 121 & -3.7168 & -3.8855 to -3.5480 & 0.8410 & 0.8391 to 0.8429 \\
3 San Nicolas, intertidal & 383 & -3.7197 & -3.7851 to -3.6544 & 0.8355 & 0.8344 to 0.8365 \\
4 San Nicolas, subtidal & 226 & -3.7647 & -3.8006 to -3.7288 & 0.8221 & 0.8211 to 0.8232 \\
5 Anacapa 1992-1993 & 230 & -3.7655 & -3.8045 to -3.7265 & 0.8284 & 0.8271 to 0.8296 \\
6 Anacapa 1993-1994 & 285 & -3.8535 & -3.8973 to -3.8097 & 0.8225 & 0.8211 to 0.8239 \\
7 San Miguel & 348 & -3.8047 & -3.8385 to -3.7710 & 0.8162 & 0.8152 to 0.8172 \\
8 Cabrillo & 687 & -3.8295 & -3.8687 to -3.7903 & 0.8370 & 0.8361 to 0.8378 \\
9 Caspar & 121 & -3.8818 & -4.1873 to -3.5763 & 0.8264 & 0.8244 to 0.8284 \\
10 Van Damme & 174 & -3.6468 & -3.7449 to -3.5487 & 0.8095 & 0.8082 to 0.8108 \\
11 Nellie's Cove & 308 & -3.7918 & -3.8718 to -3.7118 & 0.8089 & 0.8080 to 0.8098 \\
12 Long Brown & 623 & -3.8685 & -3.9405 to -3.7965 & 0.8384 & 0.8376 to 0.8392 \\
13 Selness Reef & 532 & -3.7468 & -3.8473 to -3.6463 & 0.8090 & 0.8082 to 0.8098 \\
14 North Shaw Island & 387 & -3.6885 & -3.7740 to -3.6030 & 0.8007 & 0.7998 to 0.8017 \\
15 West Shaw Island & 406 & -3.7276 & -3.8251 to -3.6300 & 0.8018 & 0.8009 to 0.8027 \\
16 Halftide Rock & 521 & -3.5915 & -3.6917 to -3.4914 & 0.8056 & 0.8048 to 0.8064 \\
17 Stomach Bay & 601 & -3.8331 & -3.8983 to -3.7679 & 0.8249 & 0.8240 to 0.8257 \\
18 Blank Island & 660 & -3.7686 & -3.8775 to -3.6598 & 0.8301 & 0.8293 to 0.8310 \\
\hline
\end{tabular}

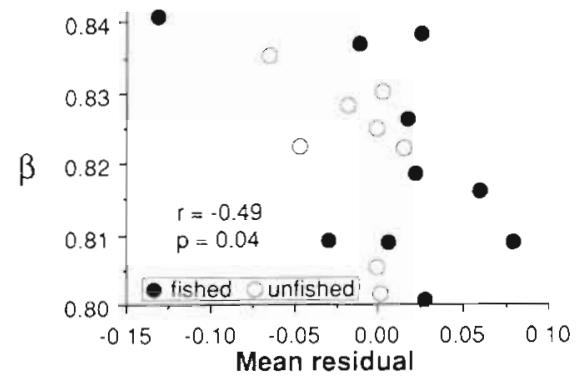

Fig. 6. Allometric exponent, $\beta$ (jaw length vs test diameter with a common intercept) related to the mean residual based on the overall nonlinear estimation of Tanaka function parameters

jaws at a given size and hence less food and slower growth rate. The relationship between $\beta$ and the mean residual for each sample using the common Tanaka parameters from Table 2 shows a negative correlation $(\mathrm{r}=-0.49, \mathrm{~N}=18, \mathrm{p}=0.04)$, which is consistent with this hypothesis (Fig. 6). Mean residuals using the common Tanaka parameters from Table 2 are small when jaws are relatively large, which suggests that variation in available food may be the driving force determining variation in growth.

The surrogate for food availability, relative jaw length, showed a trend of decreasing $\beta$ with latitude (Fig. 7), but the relationship should not be considered significant $(r=-0.36, N=18, p=0.14)$. We conclude, based on the similarity of $\beta$-values across latitude, that food resources are variable from site to site but not correlated with latitude.

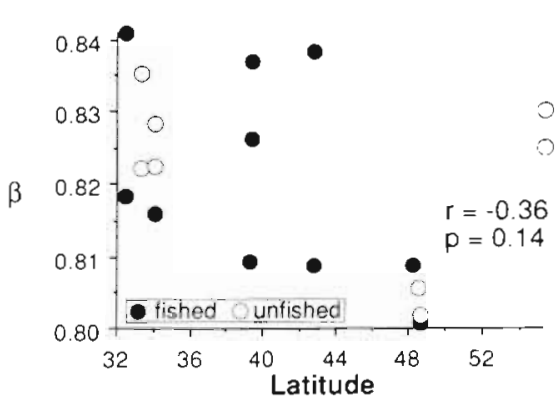

Fig. 7. Allometric exponent, $\beta$ (jaw length vs test diameter with a common intercept) related to latitude

\section{Survival rate}

Size structure was combined with growth parameters to estimate survival. The analysis required selecting size at recruitment, $S_{\mathrm{R}}$, which was taken as the mode of the smallest individuals on the day of sampling and was done by inspection of the size-frequency distributions (Figs. 8 to 11) The distributions were complicated by the additions of small sea urchins collected from outside the study sites at the time of tagging, which was done to increase resolution of the growth curve. These small individuals are shown in black in Figs. 8 \& 9 and were not included in the calculation of mean diameter; after $1 \mathrm{yr}$, however, there was no way of separating the survivors of these small sea urchins from the rest of the sample. The effect of including all individuals is to bias the estimation of the 
mean towards a smaller size and hence increase the estimate of $Z_{i}$ that is, lowering the estimate of annual survival, $p_{x}$. When added numbers were small and the samples large (e.g. Long Brown Rock, Oregon), the bias probably is undetectable. In 1992 at Nellie's Cove, Oregon, 379 resident red sea urchins were tagged and 335 additional small individuals were added. One year later, 660 sea urchins were collected at Nellie's Cove but only 38 of these were tagged and so the additional small individuals from the previous year had a negligible effect on the estimate of the mean in 1993 and we assume that the small individuals that were added to samples are not a problem. Our approach was to use mean test diameter for both original and final size distributions and so obtain 2 estimates of $Z$ for each site (Table 5).

Using Eq. (12) the instantaneous mortality rate $Z$ was estimated for samples from each location (Table 5) and then converted to $p_{x}$, which is $\mathrm{e}^{-z}$. The smallest value of $p_{x}, 0.68$, was estimated for the sample from San Miguel Island, California, and the largest value, 0.98, was for the sample at Halftide Rock, Washington.

Survival increases with increasing latitude (Fig. 12) and, once again, there is no difference between fished and unfished sites. When analysis was done as a multiple regression using $p_{x}$ as the dependent variable, and latitude, growth parameters ( $f, d$, and $a$ ), mean residual, and $\beta$ as independent variables, the only significant variable was latitude $(p=$ 0.0003 ).

The patterns that emerge from our analysis are: (1) no relationship between latitude and deviation of growth at a site from a common regression line for all 2714 tag returns; (2) latitudinal changes in parameters $f$ and $d$ of the Tanaka function, which are not directly related to average growth rates, but no latitudinal changes in $1 / \sqrt{a}$, which is related to average growth; (3) a negative relationship between relative jaw length $(\beta)$ and growth; (4) a positive relationship between survival and latitude; and (5) no differences in growth or survival estimates between fished and unfished populations.

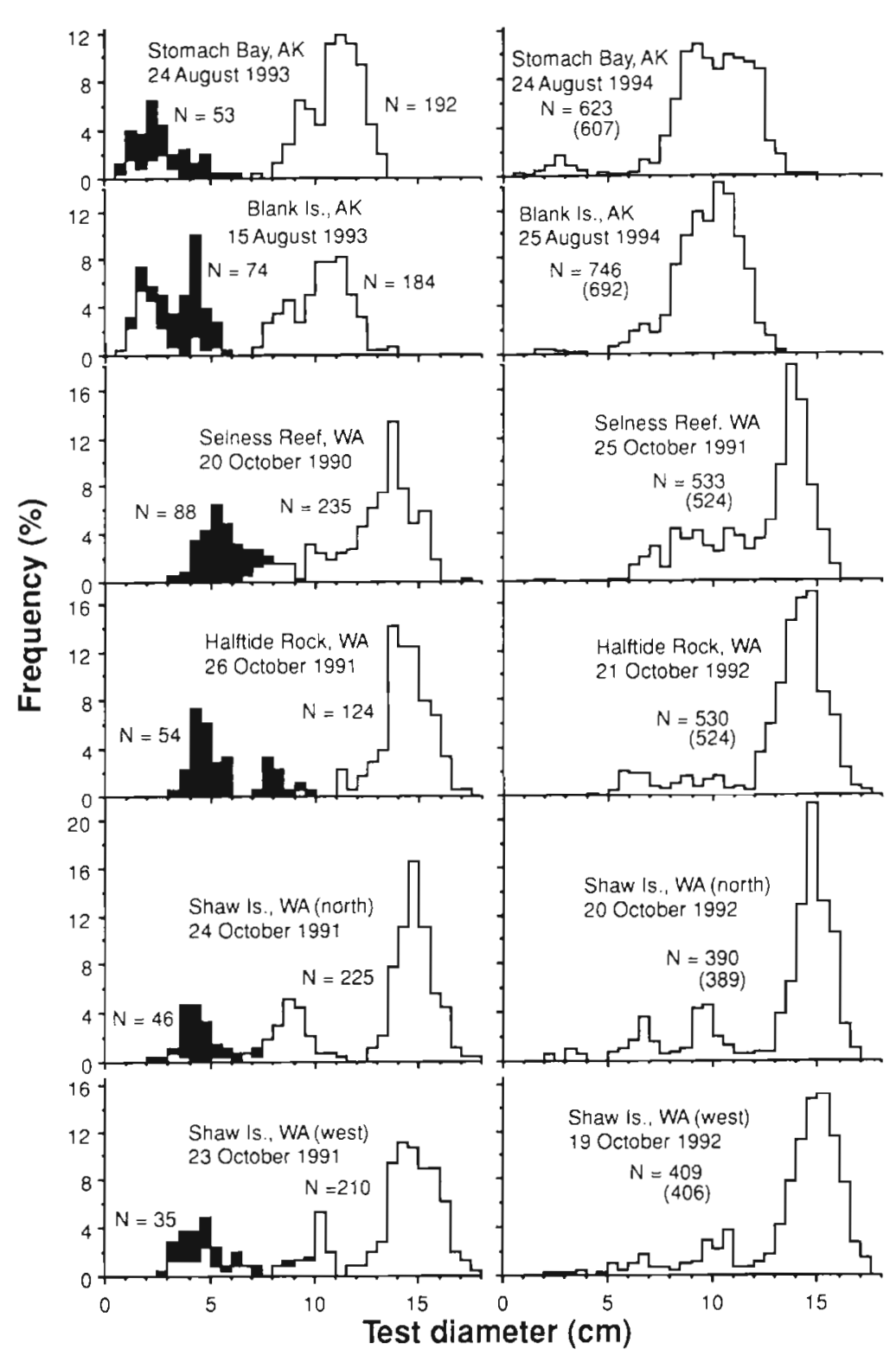

Fig. 8. Strongylocentrotus franciscanus. Size-frequency distributions of red sea urchins at study sites in Alaska and Washington; left column is size structure when urchins were tagged with tetracycline and the right column is the size structure of the sample collected approximately 1 yr later; black bars are additional small individuals that were collected from surrounding areas and added to the sample to increase resolution of growth for small individuals; $N$ is the total number of individuals forming the distribution; $N$ in parentheses is the number with both diameter and jaw measurements

\section{DISCUSSION}

Two specific issues must be addressed before discussing mechanisms to account for patterns of growth and survival: (1) the selection of the Tanaka growth model (Tanaka 1982,1988) in preference to other models such as the Richards (Richards 1959) or Brody- 


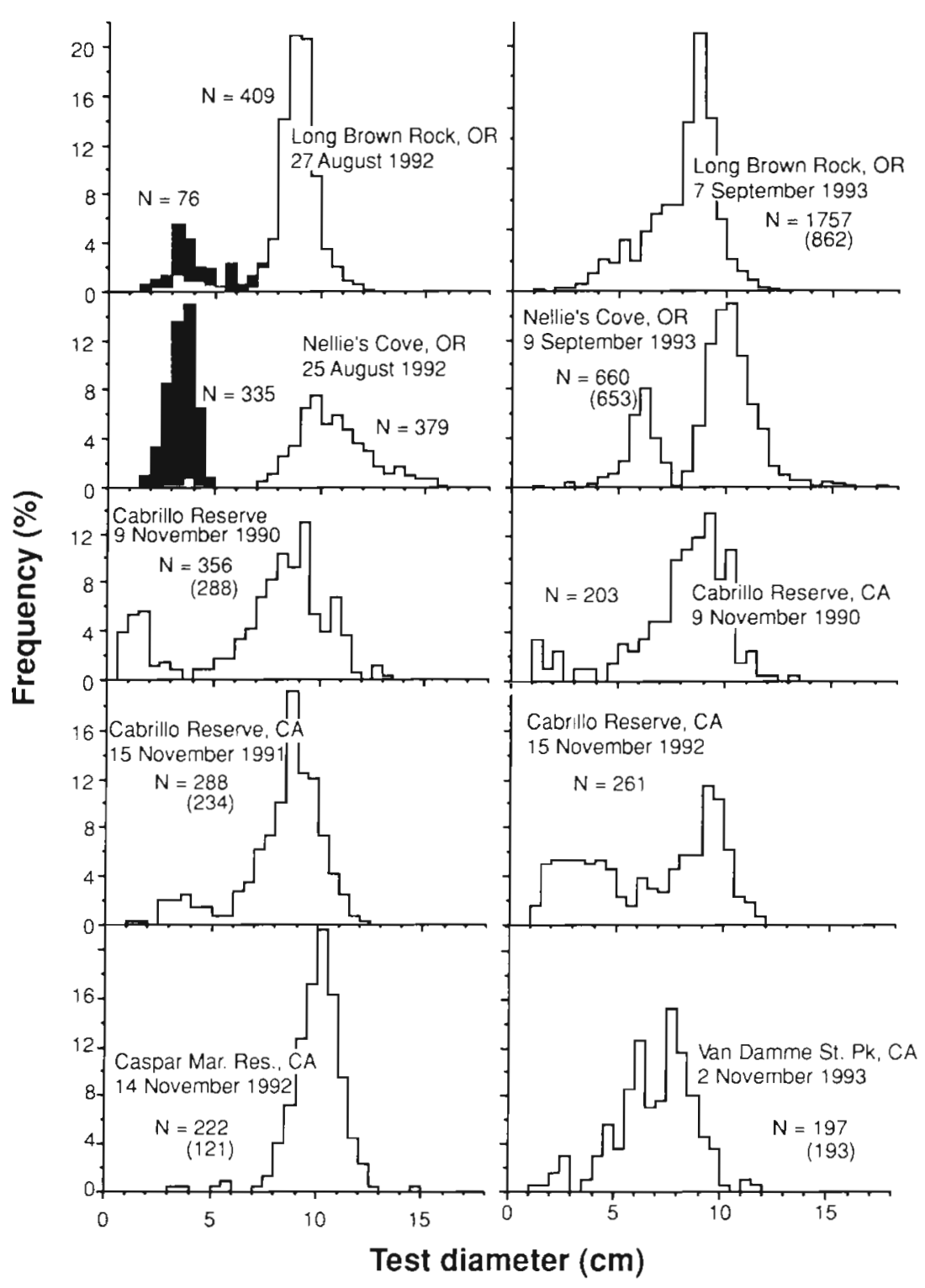

Fig. 9. Strongylocentrotus franciscanus. Size-frequency distributions of red sea urchins at study sites in Oregon and northern California; black bars are additional small individuals that were collected from surrounding areas; $N$ is the total number of individuals forming the distribution; $\mathrm{N}$ in parentheses is the number with both diameter and jaw measurements

Bertalanffy model (cf. Ricker 1975); and (2) sources of errors in estimating survival rates using means of sizefrequency distributions.

\section{The Tanaka growth model}

The selection of the Tanaka model was based on the shape of the distribution of size at $t+\Delta t$ versus size at t, which is called a Walford plot (Walford 1946). If the scatter of data points is linear, then the Brody-Bertalanffy model is appropriate. If the scatter of data points follows a non-inflected curve, then the Richards growth model or similar models (Schnute 1981, Jolicoeur 1985, Francis 1995) are appropriate; however, if the scatter of points in a Walford plot follows a curve with 1 or more inflection points, then some other model is more appropriate. The Tanaka model as a difference equation, i.e. a Walford plot, is bell-shaped and therefore may have 2 inflection points; the curve, however, is truncated at small sixes so, depending on where truncation occurs, there may be just 1 inflection point.

As was shown in the results for log-linear analysis, growth data for red sea urchins in Washington and Oregon probably can be combined. These samples have been analyzed together with additional data for 
small red sea urchins that were part of an outplant study in California; this analysis has been presented elsewhere (Ebert 1998). Growth data were first transformed to diameters and the resulting Walford graph (Fig 13) shows that the scatter of data points does not follow a straight line so the BrodyBertalanffy model is inappropriate. Also, the data appear to have an inflection point close to $8 \mathrm{~cm}$ because growth rate increases to a maximum between 3 and $4 \mathrm{~cm}$, drops over the next several $\mathrm{cm}$, but then continues out as a very long tail, which means that no shape parameters of the Richards function would be adequate.

When the Brody-Bertalanffy model was used with the data shown in Fig. $14, K=0.13 \mathrm{yr}^{-1}$ and $S_{\infty}=14.4 \mathrm{~cm}$ with a residual sum of squares $=433.5$. The residual sum of squares using the Tanaka model was 249.1, which is not quite half the value obtained using the Brody-Bertalanffy model. Clearly, the fit is better using the Tanaka function. Also, $S_{\infty}=14.4 \mathrm{~cm}$ for the Brody-Bertalanffy function is rather low given that the largest sea urchins recorded in the study were between 17 and $18 \mathrm{~cm}$ (Fig. 8)

The Brody-Bertalanffy model could be used for a curved Walford plot if the data were a mixture ranging from very fastgrowing individuals with small asymptotic sizes to very slow-growing individuals with large maximum sizes. There certainly are data that show variation in growth of sea urchins from a single cohort; Pearse \& Cameron (1991) showed that 1 yr old laboratory-reared Strongylocentrotus purpuratus had diameters that ranged from 1 to $3 \mathrm{~cm}$ and variation in growth of small red sea urchins is shown in Fig. 13. For the Brody-Bertalanffy function adequately to describe the data, variable growth for small individuals would have to be associated with variable maximum sizes so that the largest individuals would have grown very slowly and individuals that were fast growing when young stopped growing at a much smaller maximum size. No data support such a relationship for echinoderms nor is there a reasonable physiological mechanism that would explain why fast growth when small must lead to a small maximum size. If an individual shows superior growth when small, it is likely to show superior growth throughout life. If fast-growing individuals also have larger maximum sizes, then the scatter of points in a Walford plot will not follow a curve but rather will enclose a triangular region bound by straight lines. With the scatter of points shown in Fig. 13, it is more parsimonious to select the Tanaka function than to choose the Brody-Bertalanffy or Richards models and assert that there are additional and unknown associations between a growth rate constant and maximum size. Such associations would be worth exploring but at present, given the shape of the data cloud in Fig. 13, the Tanaka function is the best model. 


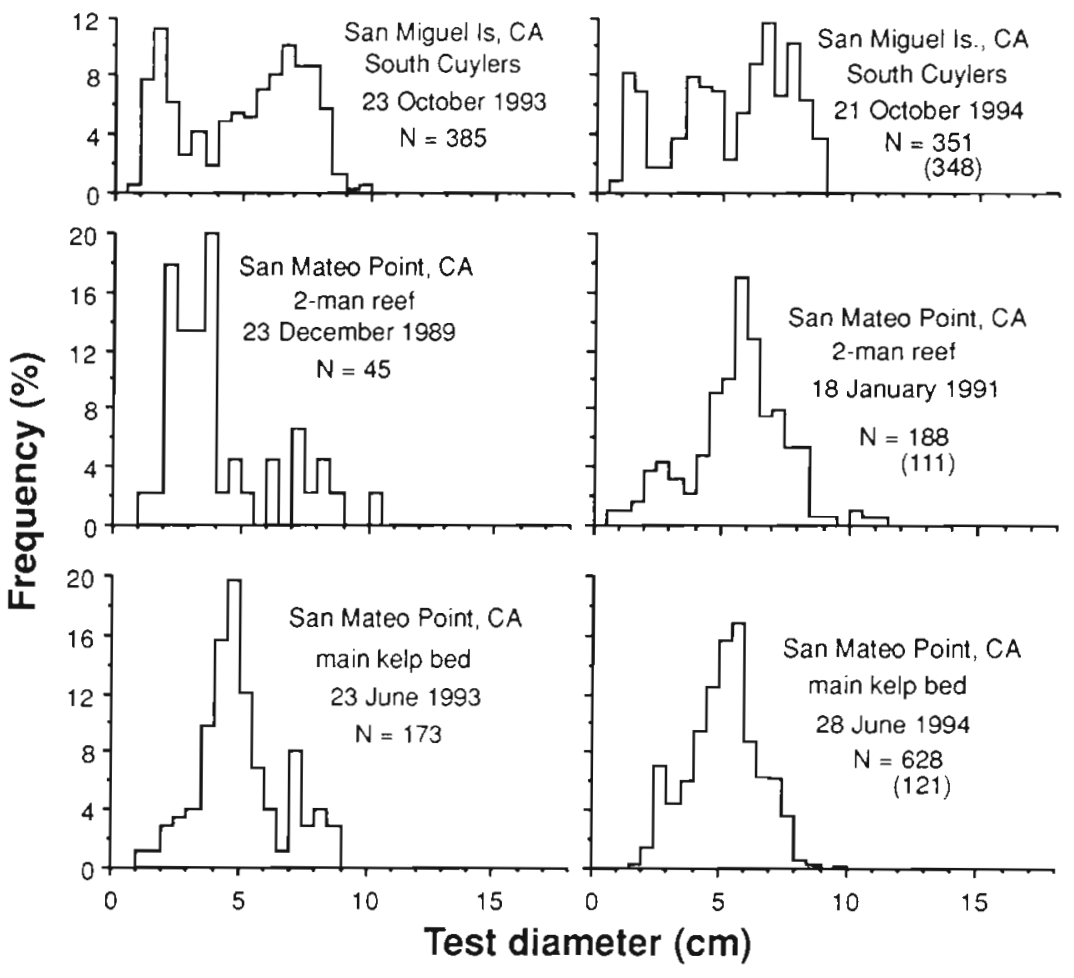

Fig. 11. Strongylocentrotus franciscanus Size-frequency distributions of red sea urchins at study sites in the Channel Islands and on the mainland of southern

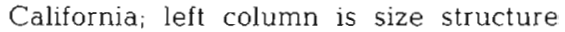
when urchins were tagged with tetracycline and the right column is the size structure approximately 1 yr lateri $\mathrm{N}$ is the total number of individuals forming the distribution; $N$ in parentheses is the number with both diameter and jaw measurements
The fitted line for the Tanaka function is shown in Fig. 13 and provides a sense of average growth so that a $4 \mathrm{~cm}$ sea urchin would grow to about $6 \mathrm{~cm}$ in 1 yr and a $6 \mathrm{~cm}$ individual to about $7.2 \mathrm{~cm}$ in the same time. A $10 \mathrm{~cm}$ sea urchin would grow to about $10.3 \mathrm{~cm}$ in $1 \mathrm{yr}$ and a $12 \mathrm{~cm}$ individual to about $12.1 \mathrm{~cm}$. Past $12 \mathrm{~cm}$, growth is very slow and annual increments are less than $1 \mathrm{~mm}$. To grow from 12 to $17 \mathrm{~cm}$ would take a long time and, because some individuals attain such a size, survival rates must be high (Ebert 1998). The growth curve based on the data presented in Fig. 13 is shown in Fig. 14 and indicates that individuals with diameters larger than $15 \mathrm{~cm}$ probably are older than $100 \mathrm{yr}$. The largest reported Strongylocentrotus franciscanus are from Alert Bay on the east side of Vancouver Island, British Columbia (Bureau 1996). In 3 samples, the largest individuals were approximately $18.3,19.0$, and $19.8 \mathrm{~cm}$. Unless growth rates are very different, the large individuals at Alert Bay are much older than $100 \mathrm{yr}$.

An age of $100+$ yr seems very old and so it is worth exploring other ways that sea urchins could become large and still be younger than 100 yr. One possibility is that sometimes conditions might be unusually good and so size would take a giant step forward. Individuals could be large not because they are old but because they had experienced 1 or more unusual growth events. During the course of our 8 yr of investigation of red sea urchin growth, we have not observed any unusual growth events and consequently, although we cannot rule them out, we have no data supporting their existence.

The growth patterns shown in Figs. 13 \& 14 are central to the estimation of survival rates using Eq. (12). The idea behind this is quite simple: with fixed growth parameters, the larger the mean size, and the greater the difference between size at recruitment and mean size, the higher survival rate must be. Using parameters determined with data in Fig. 13 (Ebert 1998), the relationship between annual survival and mean size is shown in Fig. 15. Size at recruitment, $S_{R}$, influences the estimate of annual survival and the smaller the value of $S_{R}$, the higher the estimate of survival for a given mean size. We have based selection of $S_{R}$ (Table 5) on inspection of size-frequency distributions (Figs. 8 to 11) and in doing this we are tending to underestimate survival because in all cases $S_{R}$ is larger than size of an age- 0 individual. We could use an estimate of size of sea urchins at $1 \mathrm{yr}$ for $S_{\mathrm{R}}$ however, this would make estimates of survival higher than shown in Table 5.

The very slow growth of sea urchins greater than $10 \mathrm{~cm}$ (Fig. 13) determines the relationship between mean size and survival in Fig. 15. With recruitment size at $2 \mathrm{~cm}$, annual survival must be $\geq 0.90$ for mean sizes greater than about $8.2 \mathrm{~cm}$. With recruitment size at $4 \mathrm{~cm}$, annual survival must be $\geq 0.90$ for mean sizes greater than about $9.1 \mathrm{~cm}$. If the growth data are good, and we believe that they are, then all mean sizes in 
Table 5. Strongylocentrotus franciscanus. Size data and allometric parameters for diameter as a function of jaw length (cm) that were used to estimate the instantaneous mortality rate, $Z \mathrm{yr}^{-1}$, using Eq. (12); small sea urchins were collected from surrounding areas and added to some of the study sites; measurements are in $\mathrm{cm}_{i} S_{\mathrm{R}}$ is the size at recruitment for each size distribution

\begin{tabular}{|c|c|c|c|c|c|c|}
\hline Site & $N$ & $\alpha$ & $\beta$ & $S_{R}$ & Mean & $Z \mathrm{yr}^{-1}$ \\
\hline Stomach Bay, AK, 1993 & 192 & & & 2.50 & 10.144 & 0.047 \\
\hline Additional small ind. & 53 & & & & 2.841 & \\
\hline Collection 1994 & 623 & 4.926 & 1.175 & 2.75 & 9.855 & 0.054 \\
\hline Blank Island, AK, 1993 & 184 & & & 1.8 & 8.253 & 0.064 \\
\hline Additional small ind. & 74 & & & & 3.779 & \\
\hline Collection 1994 & 746 & 4.852 & 1.145 & 2.0 & 9.691 & 0.038 \\
\hline North Shaw Island, WA 1991 & 225 & & & 3.25 & 13.225 & 0.038 \\
\hline Additional small ind. & 46 & & & & 4.522 & \\
\hline Collection 1992 & 390 & 5.535 & 1.248 & 3.25 & 13.076 & 0.040 \\
\hline West Shaw Island, WA, 1991 & 210 & & & 4.50 & 13.153 & 0.031 \\
\hline Additional small ind. & 35 & & & & 4.934 & \\
\hline Collection 1992 & 409 & 5.575 & 1.228 & 3.00 & 13.608 & 0.022 \\
\hline Half tide Rock, WA, 1991 & 124 & & & 9.0 & 14.364 & 0.016 \\
\hline Additional small ind. & 54 & & & 3.5 & 5.628 & \\
\hline Collection 1992 & 530 & 5.352 & 1.248 & 6.5 & 13.372 & 0.023 \\
\hline Selness Reef, WA, 1990 & 235 & & & 5.00 & 12.699 & 0.033 \\
\hline Additional small ind. & 88 & & & & 5.501 & \\
\hline Collection 1991 & 533 & 5.403 & 1.200 & 2.00 & 12.273 & 0.025 \\
\hline Long Brown Rock, OR, 1992 & 409 & & & 3.5 & 8.743 & 0.085 \\
\hline Additional small ind. & 76 & & & & 4.111 & \\
\hline Collection 1993 & 1757 & 4.584 & 1.140 & 1.5 & 8.005 & 0.080 \\
\hline Nellie's Cove, OR, 1992 & 379 & & & 3.75 & 10.397 & 0.099 \\
\hline Additional small ind. & 335 & & & & 3.362 & \\
\hline Collection 1993 & 660 & 5.329 & 1.212 & 2.75 & 9.292 & 0.133 \\
\hline Van Damme State Park, 1993 & 197 & 5.236 & 1.257 & 2.50 & 7.031 & 0.204 \\
\hline Pt. Cabrillo Mar. Res., CA, 1989 & 88 & & & 1.5 & 7.797 & 0.065 \\
\hline Collection 1990 & 356 & 4.542 & 1.174 & 1.5 & 7.412 & 0.077 \\
\hline Pt. Cabrillo Mar. Res., CA, 1990 & 203 & & & 1.7 & 7.980 & 0.060 \\
\hline Collection 1991 & 288 & 4.292 & 1.241 & 1.5 & 8.384 & 0.049 \\
\hline Pt. Cabrillo Mar. Res., CA, 1992 & 261 & 4.679 & 1.188 & 3.0 & 6.723 & 0.158 \\
\hline Caspar Mar. Res., CA, 1992 & 222 & 5.089 & 1.104 & 3.5 & 10.076 & 0.067 \\
\hline San Miguel Island, CA, 93 & 385 & & & 1.75 & 5.002 & 0.401 \\
\hline Collection 1994 & 351 & 5.059 & 1.209 & 1.75 & 5.256 & 0.365 \\
\hline Anacapa Island, CA, 1992 & 148 & & & 1.5 & 5.256 & 0.203 \\
\hline Collection 1993 & 359 & 4.730 & 1.204 & 1.7 & 5.418 & 0.204 \\
\hline Anacapa Island, CA, 1993 & 224 & & & 2.0 & 4.774 & 0.241 \\
\hline Collection 1994 & 327 & 4.877 & 1.183 & 2.0 & 5.261 & 0.199 \\
\hline San Nicolas Island, CA, 1989 & 188 & & & & 6.098 & \\
\hline Collection 1990 (Cosign) & 231 & 4.441 & 1.244 & 2.80 & 5.658 & 0.106 \\
\hline San Nicolas Island, CA, 1989 & 151 & & & & 7.014 & \\
\hline Collection 1990 (NW Point) & 152 & & & 2.80 & 7.015 & 0.088 \\
\hline San Nicolas Island, CA, 1990 & 276 & & & 1.80 & 5.242 & 0.292 \\
\hline Collection 1991(Block 1) & 281 & 4.896 & 1.214 & 1.80 & 5.501 & 0.264 \\
\hline San Nicolas Island, CA, 1990 & 232 & & & 1.80 & 4.931 & 0.330 \\
\hline Collection 1991(Block 2) & 249 & & & 1.80 & 5.028 & 0.317 \\
\hline San Mateo Point, CA, 1989 & 45 & & & & 4.188 & \\
\hline Collection 1.990 & 188 & 4.996 & 1.214 & 2.75 & 5.760 & 0.334 \\
\hline San Mateo Point, CA, 1993 & 173 & & & & 5.065 & 0.147 \\
\hline Collection 1994 & 628 & 4.409 & 1.168 & 2.75 & 5.212 & 0.133 \\
\hline
\end{tabular}


excess of about $10 \mathrm{~cm}$ in Oregon and Washington imply very long life.

There are important implications of slow growth and long life for management of the red sea urchin fishery. An elasticity analysis of the life cycle for Oregon and Washington populations (Ebert 1998) showed that population growth and maintenance were much more sensitive to changes in survival of individuals larger than $9 \mathrm{~cm}$ than to survival of smaller sea urchins. For example, a $10 \%$ change in survival of sea urchins $>9.0 \mathrm{~cm}$ would change population growth rate by $7.6 \%$ whereas a similar change in survival or individuals $<9.0 \mathrm{~cm}$ would change population growth by only $2.1 \%$. Conserving large individuals is very important for maintaining populations of Strongylocentrotus franciscanus from northern California northward.

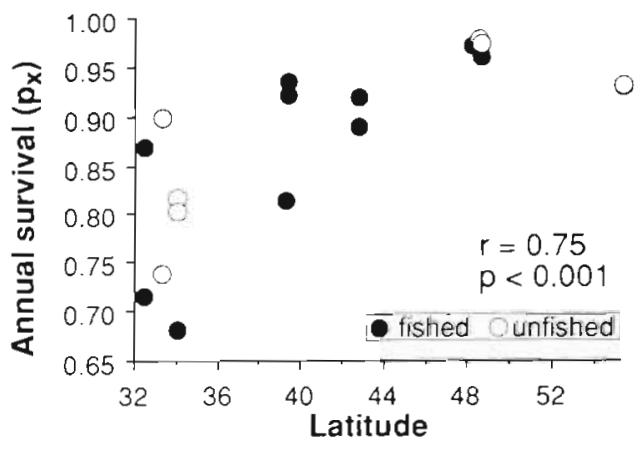

Fig. 12. Strongy/ocentrotus franciscanus. Annual survival rate for red sea urchins versus latitude

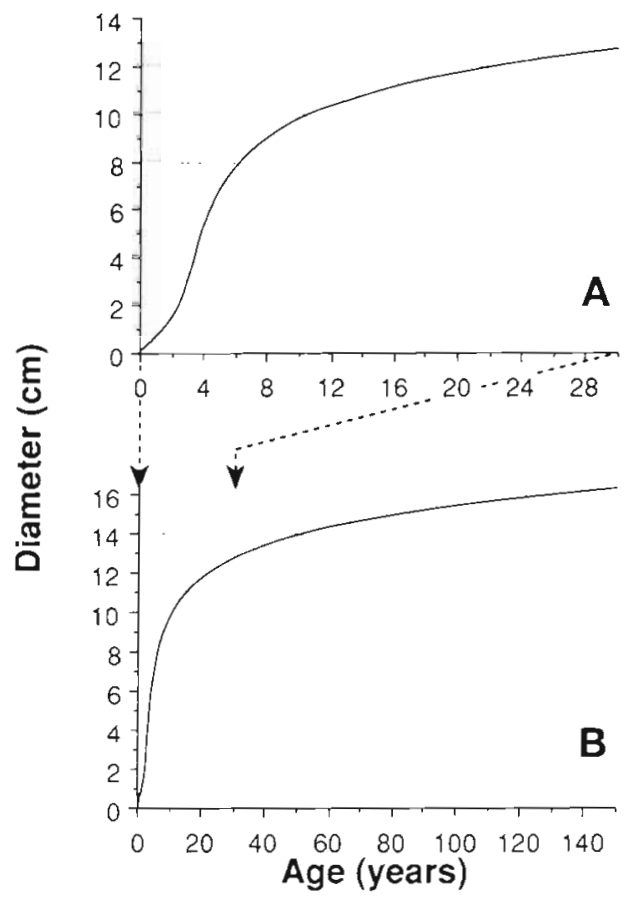

Fig. 14. Growth curves drawn using parameters of the Tanaka function shown in Fig. 13; (A) Growth out to $30 \mathrm{yr}$, and (B) same curve but with time expanded out to $150 \mathrm{yr}$; analysis presented in Ebert (1998)

Lower survival rates for $S$. franciscanus in southern California makes large individuals less important for population maintenance.

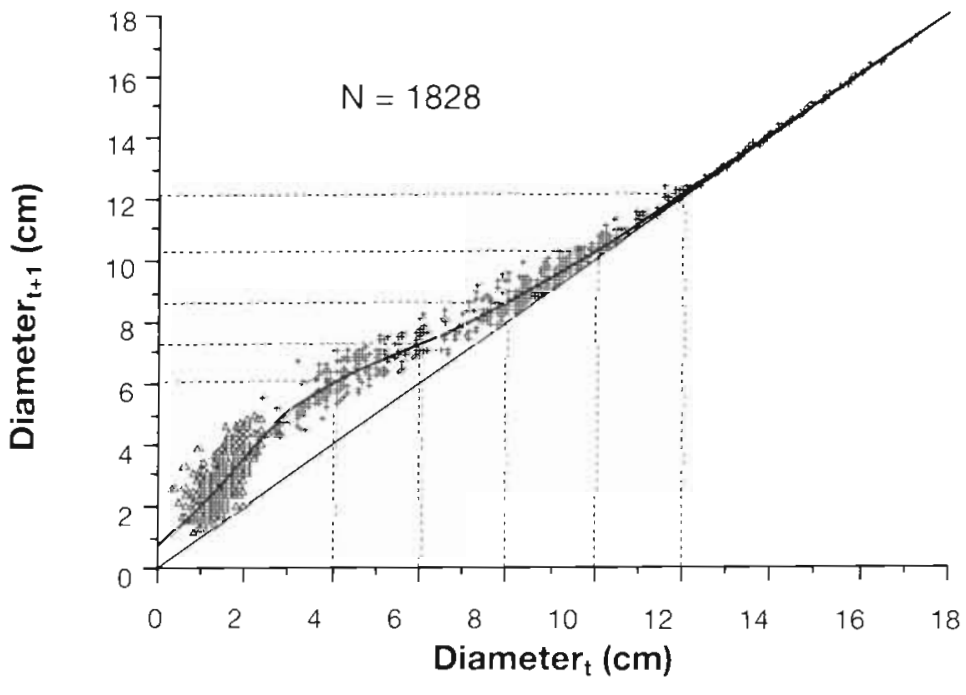

Fig. 13. Strongylocentrotus franciscanus. Test diameter of red sea urchins at time of tagging $\left(D_{1}\right)$ and diameter 1 yr later $\left(D_{t+1}\right)_{;}+=$urchins from 2 sites in Oregon and 4 in Washingion; $\Delta=$ urchins cultured at Ocean Farms of Hawaii and outplanted in California; all urchins were in the field for

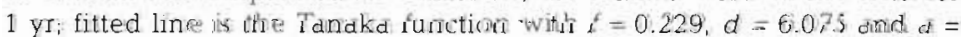
0.199 ; analysis presented in Ebert (1998)

\section{Assumptions for estimates of mortality}

Assumptions of seasonally stable and stationary size structure certainly are violated. Recruitment can be highly variable (Ebert 1983, Ebert et al. 1994) so mean sizes are expected to vary from year to year, and indeed this is shown in Figs, 8 to 11 and Table 5. There are very few longterm studies of sea urchins and none for red sea urchins, so we lack data for red sea urchins to show the extent of variability of means at a site. Purple sea urchins Strongylocentrotus purpuratus have been studied at Sunset Bay, Oregon, since 1963 and size data gathered since 1964. Ebert (1983) published size data for 1 location in Sunset Bay from 1964 to 1978. The best settlement in over 30 yr was in 1963 (Ebert unpubl.) so comparing mean size in 1964 with 1978 provides information on potential changes in mean size due to variation 


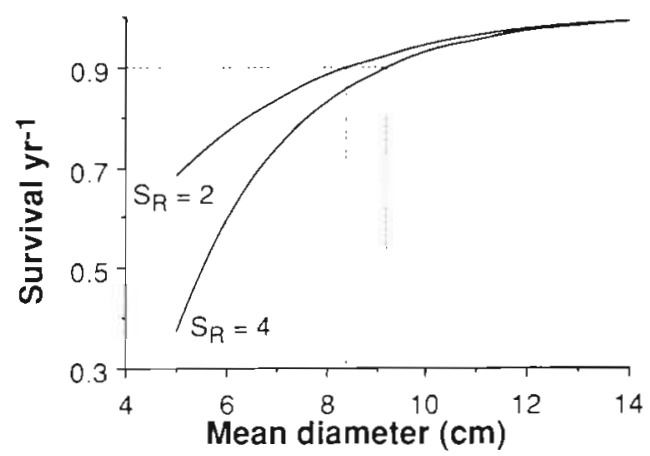

Fig. 15. Strongylocentrolus franciscanus. Relationship between annual survival rate and mean test diameter of size-frequency distributions using growth parameters from Fig. 13; $S_{\mathrm{R}}$ : size at recruitment to the population

in recruitment. The difference between mean test diameter in 1978 versus 1964 was about $30 \%$, which can be taken as the most extreme reduction that might be expected in mean sizes for red sea urchins in Oregon and Washington. At Shaw Island, where mean sizes of red sea urchins were about $13 \mathrm{~cm}$, a $30 \%$ reduction would result in a mean diameter of about 9 $\mathrm{cm}$, which, using Eq. (12), would require an annual survival rate of about $90 \%$ (Fig 15). With the growth characteristics shown in Fig. 16, mean sizes can vary by a centimeter or two without changing the general conclusion of long life.

Unusual recruitment events imply that red sea urchins probably never have a population growth rate, $\lambda$, equal to 1.0 . In general, populations probably are declining in between episodes of heavy recruitment. If populations persist, then how rapidly they decline must match the frequency of heavy recruitment events. If events are infrequent, the decline must be very slow and hence the population growth rate must be close to 1.0. More frequent major settlement events would be present in populations with higher rates of mortality, which probably is true in southern California where good settlement occurs more frequently (Ebert et al. 1994). Overall, the mean sizes we used in estimating survival represent samples of some grand mean that would exist over many years. Our samples are more likely to lie close to this grand mean though this is by no means certain.

Changes of shape of growth curves with latitude as shown by the correlations of Tanaka parameters $f$ and $d$ are puzzling. The trend is illustrated by using Tanaka parameters for the most extreme estimates of $f$, 13.935 for Halftide Rock in Washington and 2.315 for the 1993-1994 sample at Anacapa Island, California (Fig. 16). We propose that the correlation of parameters $f$ and $d$ with latitude is caused by having increased numbers of large tagged individuals in northern sam- ples and a lack of very small individuals in all samples The presence of large individuals would tend to hold a fitted line close to the $45^{\circ}$ slope in Figs. 4 or 13 and hence increase a long tail. This is exactly the meaning of a large value of $f$. If there are very few large individuals in a sample, a long tail is less likely to be estimated. The correlations of $f$ and $d$ with latitude probably should be considered to be consequences of the data structure and not to have biological meaning other than indicating the presence of large and very old sea urchins at northern sites. Our sense is that if our data included very small individuals at all sites and survival was better in the south so large individuals would be present, then the correlations between $f$ and $d$ with latitude would disappear. It is possible, of course, that the correlations are not just consequences of the data structure, in which case they pose a wonderful puzzle as to biological basis and evolutionary significance, if any.

\section{Mechanisms to account for differences in the latitudinal patterns of growth and mortality}

The red sea urchin shows differences in growth and survival over a substantial portion of its geographic range; differences in growth, however, can be as great over very short distances as over more than $20^{\circ}$ of latitude. We found no latitudinal pattern for growth and so our results differ from many other studies of marine species such as Weymouth et al. (1931), Frank (1975) or Harrington (1987) for molluscs or Leggett \& Carscadden (1978) or Jonsson \& L'Abée-Lund (1993) for fish. On the other hand, our results are similar to those presented by Russell (1987) for the purple sea urchin Strongylocentrotus purpuratus or by MacDonald \&

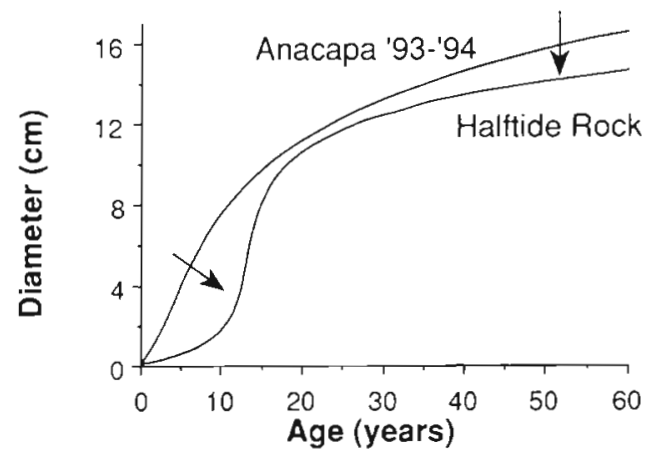

Fig. 16. Strongylocentrotus franciscanus. Growth curves for extreme values of the Tanaka parameter f: 2.315 for Anacapa 1993-1994 in southern California and 13.935 for Halftide Rock in Washington; arrows indicate the direction of change in shape, which is the meaning of the latitudinal correlation shown in Fig. 5 
Thompson (1988) for the scallop Placopecten magellanicus. In both of these studies, local variation in growth was as great as differences across many degrees of latitude.

Growth of Strongylocentrotus franciscanus can have the same expression from southern California to Alaska and so any temperature effect on growth is obscured by the effects of other factors. Growth of $S$. franciscanus was correlated with the allometric exponent $\beta$ for relative jaw size; relative jaw length and growth have been shown to vary with food availability in this species (Bureau 1996) as well as in S. purpuratus (Fansler 1983, Edwards \& Ebert 1991, Ebert 1996), Echinometra mathaei (Black et al, 1982, 1984) and Diadema antillarum (Levitan 1989). The lack of a strong latitudinal correlation between $\beta$ and latitude (Fig. 8) argues against latitudinal differences in food availability, which has been suggested for other species (Frank 1975, Clarke 1982). The lack of a correlation between $\beta$ and latitude also argues against food limitation as a cause of increasing mortality in the south.

Most explanations for increased mortality at southern locations along the Pacific coast have focused on a causal relationship between rapid growth and increased mortality (Harrington 1987) or on predators that change with latitude (Frank 1975, Fawcett 1984, Tegner 1989). For sea urchins, potential southern predators include lobsters (Tegner \& Levin 1983) and a large wrasse, the sheephead (Cowen 1983). Both lobsters and sheephead are heavily fished in southern California so their current contributions to sea urchin mortality are uncertain.

Disease is another mechanism that might account for latitudinal differences in mortality and various pathogens are known to cause diseases in echinoderms (Gilles \& Pearse 1986, Harrold \& Pearse 1987, Jangoux 1987, Tajima et al. 1997). Outbreaks of disease have been correlated with elevated sea temperatures in Nova Scotia (Scheibling 1984, Scheibling \& Stephenson 1984) and Japan (Tajima et al. 1997) and so it is possible that higher temperatures in southern California may result in greater frequency and severity of sea urchin diseases. Reports of disease include a mass die-off in kelp beds of southern California (Johnson 1971) and localized mortalities in central California in 1976 at Año Nuevo Island (Fig. 1) and Santa Cruz Point (Pearse et al. 1977). There have not been any mass mortalities in central California reported after 1976 (J Pearse pers. comm.). In contrast, there are many more reports of disease outbreaks south of Point Conception, California. In addition to the reported mortality off San Diego in 1970 (Johnson 1971), Foster \& Schiel (1992) found dead Strongylocentrotus francisCanus at Santa Catalina Island associated with the elevated sea temperatures of the 1982-1983 El Niño.
Large numbers of dead sea urchins, mostly $S$. franciscanus, were observed at a depth of about $12 \mathrm{~m}$ in Bahia Soledad (3135' N, Fig. 1), in July 1983 (R. McPeak pers. comm.) and dead S. purpuratus and S. franciscanus were observed in the Mission Bay channel (San Diego, CA) in 1997 (C. Gramlich pers. comm.). Similar mortalities were observed offshore in 1997 in the La Jolla and Point Loma kelp beds of San Diego (D. Datz pers. comm, S. Schroeter \& J. Dixon pers. obs.).

A clear link between temperature and disease in sea urchins is provided by Tajima et al. (1997), who reported that a disease has occurred in culture systems for Strongylocentrotus intermedius and Pseudocentrotus depressus since the 1980 s and usually during late July through August when coastal sea temperatures rise above $20^{\circ} \mathrm{C}$. These authors isolated a gliding bacterium (family Cytophagaceae) and, following infection, observed no mortality of sea urchins at $20^{\circ} \mathrm{C}$ but $100 \%$ at 23 and $25^{\circ} \mathrm{C}$.

It is also possible that high temperatures alone could account for latitudinal differences in mortality. Lawrence (1996) has reviewed the role of abiotic factors and provides examples of mass mortality in the subtidal correlated with elevated temperatures. Ford et al. (1978) showed that prolonged exposure to temperatures higher than 22 to $23^{\circ} \mathrm{C}$ resulted in high mortalities for both Strongylocentrotus purpuratus and $S$. franciscanus and that loss of spines and failure to hold spines erect were common among individuals following exposure to temperatures of about $22^{\circ} \mathrm{C}$, which occur in surface waters in southern California. During a 9 yr period from 1969 to 1977 , average monthly sea surface temperatures reached $23^{\circ} \mathrm{C}$ during the 3 summers (Ebert 1983). At a depth of $5 \mathrm{~m}$ daily means often exceed $21^{\circ} \mathrm{C}$ and maximum daily values over $23^{\circ} \mathrm{C}$ occur (e.g. Walker et al. 1991, 1993, 1994, 1995). If there are increased deaths at temperatures above 22 to $23^{\circ} \mathrm{C}$, it is reasonable to expect increased stress at somewhat lower temperatures.

Our argument now follows Scheibling (1984) and Scheibling \& Stephenson (1984). We suggest that higher temperatures in the southern California Bight provide a stress not experienced by sea urchins at sites north of Point Conception, and would promote more frequent outbreaks of disease. Elevated temperatures associated with El Niño conditions would have the potential of promoting mass mortality of sea urchin populations 2 or more times each decade and under these conditions, populations of long-lived species, such as Strongylocentrotus franciscanus, would never achieve a stable-size configuration nor, in general, have a population growth rate per individual ('little $r$ ') of zero. They would tend to increase until the next plague reduced the population. With $r>0$, there would be relatively more small individuals in a population 
and hence mean size would be smaller than in a population with similar growth and survival characteristics. The smaller mean size would cause $Z$ to be overestimated and hence $p_{x}$ to be underestimated. Disease incidence mediated by temperature is a reasonable candidate for explaining north-south differences in the estimates of mortality.

Oux original goal was just to test the hypothesis that growth and survival of red sea urchins were correlated with latitude. There is a clear positive correlation between survival and latitude. The biological basis for higher survival in the north, however, is unknown. Whether the proximate causes of death involve diseases or warm sea temperatures, or combinations of these, is unclear but represents a reasonable explanation. Although growth analysis turned out to be substantially more complex than expected, it provides compelling evidence that growth rate does not vary with latitude. Results of the log-linear analysis indicated no latitudinal pattern and was supported by analysis of residuals from a common growth equation and individual estimates of maximum growth rate. The correlation between growth and relative jaw size suggests that the driving force for growth differences is food availability, which is not correlated with latitude. Because the purple sea urchin Strongylocentrotus purpuratus shows a similar latitudinal pattern with respect to growth and survival (Russell 1987), we speculate that there may be an important phylogenetic component and at least other members of the genus Strongylocentrotus may also have growth with temperature compensation and no latitudinal pattern. More largescale studies of growth and survival for a range of species are needed before patterns and levels of phenotypic plasticity and causes of mortality become known.

Acknowledgements. This study was dependent on the efforts, funding, and logistical support of many people and institutions. Data synthesis was supported by funds from the Pacific States Fishery Commission. Funding for work in Oregon was provided by Oregon Sea Urchin Commodity Commission and Oregon State University Sea Grant. Funding in California was from self-imposed landing-tax funds administrated by the California Department of Fish and Game and, at San Nicolas Island, by funds from the US Fish and Wildlife Service. Work in the field was also supported by state employees and local fishermen. Processing sea urchins for growth analysis was done by J. Wolf, and J. Crooks brought the Tanaka function to our attention. The manuscript benefited from comments made by $M$. Russell plus a number of anonymous reviewers. We truly appreciate fll of the support we have received.

\section{LITERATURE CITED}

Baker SL (1973) Growth of the red sea urchin Strongylocentrotus franciscanus in two natural habitats. MS thesis, San Diego State University, San Diego, CA.
Bavestrello G, Cattaneo-Vietti R, Cerrano C, Sarà M (1993) Rate of spiculogenesis in Clathrina cerebrum (Porifera: Calcispongiae) using tetracycline marking. I Mar Biol Assoc UK 73:457-460

Bazhin AG (1998) The sea urchin genus Strongylocentrotus in the sea of Russia: taxonomy and ranges. In: Mooi R, Telford $M$ (eds) Echinoderms: San Francisco. Proceedings. 9th International Echinoderm Conference. A. A. Balkema, Brookfield, VT, p 563-566

Bigelow KA (1993) Age and growth of the oceanic squid Onychoteuthis borealijaponica in the North Pacific. Fish Bull US 92:13-25

Black R, Johnson MS, Trendall JT (1982) Relative size of Aristotle's lantern in Echinometra mathaei occurring at different densities. Mar Biol 71:101-106

Black R, Codd C, Hebbert D, Vink, S, Burt J (1984) The functional significance of the relative size of Aristotle's Lantern in the sea urchin Echinometra mathaei (de Blainville). J Exp Mar Biol Ecol 77:81-97

Botsford LW, Quinn JF, Wing SR, Brittnacher JG (1993) Rotating spatial harvest of a benthic invertebrate, the red sea urchin, Strongylocentrotus franciscanus. In: Eggers DM, Kruse G, Marasco RJ, Pautzke C, Quinn JT (eds) Proc International Symp Management Strategies for Exploited Fish Populations. Alaska Sea Grant College Program AKSG-93-02. University of Alaska, Fairbanks, p 409-428

Botsford LW, Smith BD, Quinn JF (1994) Bimodality in size distributions: the red sea urchin Strongylocentrotus franciscanus as an example. Ecol Appl 4:42-50

Briggs JC (1974) Marine zoogeography. McGraw-Hill, New York

Bullock TH (1955) Compensation for temperature in the metabolism and activity of poikilotherms. Biol Rev 30: $311-342$

Bureau D (1996) Relationship between feeding, reproductive condition, jaw size and density in the red sea urchin, Strongylocentrotus franciscanus. MS thesis, Simon Fraser University, Burnaby, BC

Caswell H (1989) Matrix population models. Sinauer Associates, Sunderland, $\mathrm{MA}$

Clarke A (1982) Temperature and embryonic development in polar marine invertebrates. Int J Invertebr Reprod 5:71-82

Cowen RK (1983) The effect of sheephead (Semicossyphus pulcher) predation on red sea urchin (Strongylocentrotus franciscanus) populations: an experimental analysis. Oecologia 58:249-255

Dafni J (1992) Growth rate of the sea urchin Tripneustes gratilla elatensis. Isr J Zool 38:25-33

Duineveld GCA, Jenness MI (1984) Differences in growth rates of the sea urchin Echinocardium cordatum as estimated by the parameter $\omega$ of the von Bertalanffy equation applied to skeletal rings. Mar Ecol Prog Ser 19:65-72

Durham, JW, Wagner CD, Abbott DP (1980) Echinoidea: the sea urchins. In: Morris RH, Abbott DP, Haderlie EC (eds) Intertidal invertebrates of California. Stanford University Press, Stanford, CA, p 160-176

Ebert TA (1975) Growth and mortality in postlarval echinoids. Am Zool 15:755-775

Ebert TA (1977) An experimental analysis of sea urchin dynamics and community interactions on a rock jetty. J Exp Mar Biol Ecol 27:1-22

Ebert TA (1980a) Estimating parameters in a flexible growth equation, the Richards function. Can J Fish Aquat Sci 37: $687-692$

Ebert TA (1980b) Relative growth of sea urchin jaws: an example of plastic resource allocation. Bull Mar Sci 30: $467-474$ 
Ebert TA (1982) Longevity, life history, and relative body wall size in sea urchins. Ecol Monogr 52:353-394

Ebert TA (1983) Recruitment in echinoderms. Echinoderm Stud 1:169-203

Ebert TA (1987) Estimating growth and survival parameters by nonlinear regression using average size in catches. In: Pauly D, Morgan GR (eds) Theory and application of length-based methods in stock assessment. ICLARM Conference Proceedings 13. International Center for Living Aquatic Resources Management, Manila, p 35-44

Ebert TA (1988) Calibration of natural growth lines in ossicles of two sea urchins, Strongylocentrotus purpuratus and Echinometra mathaei, using tetracycline. In: Burke RD, Mladenov PV, Lambert P, Parsley RL (eds) Echinoderm biology: Proceedings, 6th International Echinoderm Conference. A. A. Balkema, Rotterdam, p 435-443

Ebert TA (1996) Adaptive aspects of phenotypic plasticity in echinoderms. Oceanol Acta 19:347-355

Ebert TA (1998) An analysis of the importance of Allee effects in management of the red sea urchin Strongylocentrotus franciscanus. In: Mooi R, Telford M (eds) Echinoderms: San Francisco. Proceedings 9th International Echinoderm Conference. A. A. Balkema, Brookfield, VT, p 619-627

Ebert TA (1999) Plant and animal populations. Methods in demography. Academic Press, San Diego, CA

Ebert TA, Russell MP (1992) Growth and mortality estimates for red sea urchin, Strongylocentrotus franciscanus, from San Nicolas Island, California. Mar Ecol Prog Ser 81:31-41

Ebert TA, Russell MP (1993) Growth and mortality of subtidal red sea urchins (Strongylocentrotus franciscamus) at San Nicolas Island, California, USA: problems with models. Mar Biol 117:79-89

Ebert TA, Schroeter SC, Dixon JD, Kalvass P (1994) Settlement patterns of red and purple sea urchins (Strongylocentrotus franciscanus and S. purpuratus) in California, USA. Mar Ecol Prog Ser 111:41-52

Edwards PB, Ebert TA (1991) Plastic responses to limited food availability and spine damage in the sea urchin Strongylocentrotus purpuratus. J Exp Mar Biol Ecol 145:205-220

Estes JA, Duggins DO (1995) Sea otters and kelp forests in Alaska: generality and variation in a community ecological paradigm. Ecol Monogr 65:75-100

Fansler SC (1983) Phenotypic plasticity of skeletal elements in the purple sea urchin, Strongylocentrotus purpuratus. MS thesis, San Diego State University, San Diego, CA

Fawcett $\mathrm{MH}$ (1984) Local and latitudinal variation in predation on an herbivorous marine snail. Ecology 65: $1214-1230$

Ford RF, Foreman DG, Grubbs KJ, Kroll CD, Watts DG (1978) Effects of thermal effluent on benthic marine invertebrates determined from long-term simulation studies. In: Thorp JH, Gibbons JW (eds) Energy and environmental stress in aquatic systems. CONF-771114. Tech. Information Center. US Dept Energy, Springfield, VA, p 546-568

Foster MS, Schiel DR (1992) Zonation, El Niño disturbance, and the dynamics of subtidal vegetation along a $30 \mathrm{~m}$ depth gradient in two giant kelp forests. In: Battershill $C N$, Schiel DR, Jones DG, Creese RG, MacDiarmid AB (eds) Proc Second Int Temperate Reef Symp. National Institute of Water and Atmospheric Research (NIWA) Marine, Wellington, NZ, p 151-162

Francis RICC (1995) An alternative mark-recapture analogue of Schnute's growth model. Fish Res 23:95-111

Frank PW (1975) Latitudinal variation in the life history features of the black turban snail Tegula funebralis (Prosobranchia: Trochidae). Mar Biol 31:181-192

Gage JD (1987) Growth of the deep-sea irregular sea urchins
Echinosigra phiale and Hemiaster espergitus in the Rockall Trough (N. E. Atlantic Ocean). Mar Biol 96:19-30

Gage JD (1992) Natural growth bands and growth variability in the sea urchin Echinus esculentus: results from tetracycline tagging. Mar Biol 114:607-616

Gage JD (1995) Demographic modelling in the analysis of population dynamics of deep-sea macrobenthos. Int Rev Hydrobiol 80:171-185

Gebauer P. Moreno CA (1995) Experimental validation of the growth rings of Loxechinus albus (Molina, 1782) in southern Chile (Echinodermata: Echinoidea). Fish Res 21: 423-435

Gilles KW, Pearse JS (1986) Studies on disease in sea urchins, Strongylocentrotus purpuratus: experimental infection and bacterial virulence. Dis Aquat Org 1:105-114

Harrington RJ (1987) Skeletal growth histories of Protothaca staminea (Conrad) and Protothaca grata (Say) throughout their geographic ranges, northeastern Pacific. Veliger 30 : $148-158$

Harrold C, Pearse JS (1987) The ecological role of echinoderms in kelp forests. Echinoderm Stud 2:137-233

Jangoux $M$ (1987) Diseases of echinodermata. I. Agents microorganisms and protistans. Dis Aquat Org 2:147-1.62

Johnson PT (1971) Studies on diseased urchins from Point Loma. In: North WJ (ed) Kelp habitat improvement project. Annual Report 1 July 1970-30 June 1971. WM Keck Laboratory of Environmental Health Engineering. California Institute of Technology, Pasadena, CA, p 82-90

Jolicoeur P (1985) A flexible 3-parameter curve for limited or unlimited somatic growth. Growth 49:271-281

Jonsson B, L'Abée-Lund JH (1993) Latitudinal clines in lifehistory variables of anadromous brown trout in Europe. J Fish Biol 43(Suppl A):1-16

Karlson RH, Levitan DR (1990) Recruitment-limitation in open populations of Diadema antillarum: an evaluation. Oecologia 82:40-44

Kenner MC (1992) Population dynamics of the sea urchin Strongylocentrotus purpuratus in a central California kelp forest: recruitment, mortality, growth, and diet. Mar Biol 112:107-118

Kinne O (1970) Temperature. In: Kinne O (ed) Marine ecology, Vol 1, Environmental factors, Part 1 Wiley-Interscience, New York, p 407-514

Kobayashi S, Taki J (1969) Calcification in sea urchins I. A. tetracycline investigation of growth of the mature test in Strongylocentrotus intermedius. Calcif Tissue Res 4 $210-223$

Lawrence JM (1996) Mass mortality of echinoderms from abiotic factors. Echinoderm Stud 5:103-137

Leggett WC, Carscadden JE (1978) Latitudinal variation in reproductive characteristics of American shad (Alosa sapidissima): evidence for population specific life history strategies in fish. J Fish Res Board Can 35:1469-1478

Leighton DL (1967) Ecological investigations of sea urchin populations along the Palos Verdes peninsula. In: North WJ (principal investigator) kelp habitat improvement project, Annual Report 1966-67. California Institute of Technology, Pasadena, CA, p 41-54

Levitan DR (1989) Density-dependent size regulation in Diadema antillarum: effects on fecundity and survivorship. Ecology 70:1414-1424

Lonsdale DJ, Levinton JS (1985) Latitudinal differentiation in copepod growth: an adaptation to temperature. Ecology $66: 1397-1407$

Low CJ (1975) The effect of grouping of Strongylocentrotus franciscanus, the giant red sea urchin, on its population biology. PhD thesis, Univ British Columbia, Vancouver 
MacDonald BA, Thompson RJ (1988) Intraspecific variation in growth and reproduction in latitudinally differentiated populations of the giant scallop Placopecten magellanicus (Gmelin). Biol Bull 175:361-371

Milliken GA, Johnson DE (1984) Analysis of messy data. Lifetime Learning Publications, Belmont, CA

Mortensen Th (1943) A monograph of the Erhinoidea, Vol III, Part 3. Camarodonta II. Echinidae, Strongylocentrotidae, Parasaleniidae, Echinometridae. CA Reitzel, Copenhagen

Nakahara $\mathrm{H}$ (1961) Determination of growth rates of nacreous layer by the administration of tetracycline. Bull Natl Pearl Res Lab 6:607-614

Nichols D, Sime AAT, Bishop GM. (1985) Growth in populations of the sea-urchin Echinus esculentus L. (Echinodermata: Echinoidea) from the English Channel and Firth of Clyde. J Exp Mar Biol Ecol 86:219-228

Owen RW (1980) Eddies of the California Current System: physical and ecological characteristics. In: Power DM (ed) The California Islands. Santa Barbara Museum of Natural History, Santa Barbara, CA, p 237-263

Pauly D (1980) On the interrelationships between natural mortality, growth parameters, and mean environmental temperature in 175 fish stocks. J Cons Int Explor Mer 39: $175-192$

Pearl R (1928) The rate of living. A. A. Knopf, New York

Pearse JS, Cameron RA (1991) Echinodermata: Echinoidea. In: Giese AC, Pearse JS, Pearse VB (eds) Reproduction of marine invertebrates, Vol VI. Echinoderms and lophophorates. Boxwood Press, Pacific Grove, CA

Pearse JS, Costa DP, Yellin MB, Agegian CR (1977) Localized mass mortality of red sea urchin, Strongylocentrotus franciscanus, near Santa Cruz, California. Fish Bull 53: $645-648$

Richards FJ (1959) A flexible growth function for empirical use. J Exp Bot 10:290-300

Ricker WE (1975) Computation and interpretation of biological statistics of fish populations. Bull Fish Res Board Can 191

Rowley RJ (1990) Newly settled sea urchins in a kelp bed and urchin barren ground: a comparison of growth and mortality. Mar Ecol Prog Ser 62:229-240

Russell MP (1987) Life history traits and resource allocation in the purple sea urchin, Strongylocentrotus purpuratus (Stimpson). J Exp Mar Biol Ecol 108:199-216

SAS Institute (1988) SAS/STAT Users guide, Release 6.03 edn. SAS, Cary, NC

Scheibling RE (1984) Echinoids, epizootics and ecological stability in the rocky subtidal off Nova Scotia, Canada. Helgol Wiss Meeresunters 37:233-242

Scheibling RE, Stephenson RL (1984) Mass mortality of Strongylocentrotus droebachiensis (Echinodermata: Echinoidea) off Nova Scotia, Canada. Mar Biol 78:153-164

Schnute J (1981) A versatile growth model with statistically stable parameters. Can J Fish Aquat Sci 38:1128-1140

Schroeter SC (1978) Experimental studies of competition as a factor affecting the distribution and abundance of purple

Editorial responsibility: Otto Kinne (Editor),

Oldendort/Luhe, Germany sea urchins, Strongylocentrotus purpuratus (Stimpson). PhD thesis, Univ California, Santa Barbara, CA

Spangenberg DB, Beck CW (1972) Tetracycline effects on statolith and nematocyst differentiation in Aurelia. Calcif Tissue Res 9:122-130

Swan EF (1961) Some observations on the growth rate of sea urchins in the genus Strongylocentrotus. Biol Bull 120: $420-427$

SYSTAT (1992) Statistics, Version 5.2. SYSTAT Inc, Evanston, IL

Tajima T, Hirano T, Motohiro S, Ezura Y (1997) Isolation and pathogenicity of the causative bacterium of spotting disease of sea urchin Strongylocentrotus intermedrus. Fish Sci 63:249-252

Tanaka M (1982) A new growth curve which expresses infinite increase. Publ Amakusa Mar Biol Lab 6:167-177

Tanaka M (1988) Eco-physiological meaning of parameters of ALOG growth curve. Publ Amakusa Mar Biol Lab 9: 103-106

Tegner $M(1989)$ The feasibility of enhancing red sea urchin, Strongylocentrotus franciscanus, stocks in California: an analysis of the options. Mar Fish Rev 51:1-22

Tegner MJ, Levin LA (1983) Spiny lobsters and sea urchins: analysis of a predator-prey interaction. J Exp Mar Biol Ecol 73:125-150

Turon X, Giribet G, López S, Palacin C (1995) Growth and population structure of Paracentrotus lividus (Echinodermata: Echinoidea) in two contrasting habitats. Mar Ecol Prog Ser 122:193-204

Walford LA (1946) A new graphic method of describing the growth of animals. Biol Bull 90:141-147

Walker MM (1981) Influence of season on growth of the sea urchin Evechinus chloroticus. NZ J Mar Freshwat Res 15: 201-205

Walker PW, Stewart EF, Montyla AW (1.991) Surface water temperatures, salinities, and densities at shore stations United States West Coast 1990. SIO Reference 91-10. University of California Scripps Institution of Oceanography, La Jolla, CA

Walker PW, Newton DM, Montyla AW (1993) Surface water temperatures, salinities, and densities at shore stations United States West Coast 1992. SIO Reference 93-18. University of California Scripps Institution of Oceanography, La Jolla, CA

Walker PW, Newton DM, Montyla AW (1994) Surface water temperatures, salinities, and densities at shore stations United States West Coast 1992. SIO Reference 94-9, University of California Scripps Institution of Oceanography, La Jolla, CA

Walker PW, Fey CL, Newton DM (1995) Surface water temperatures, salinities, and densities at shore stations United States West Coast 1994. SIO Reference 95-30. University of California Scripps Institution of Oceanography, La Jolla, CA

Weymouth FW, MCMillin HC, Rich WH (1931) Latitude and relative growth in the razor clam. Siliqua patula. I Exp Biol 8:228-249

Submitted: November 17, 1998; Accepted: June 16, 1999 Proofs received from author(s): November 29, 1999 